\title{
La transición Paracas-Nasca en los valles de Palpa
}

\author{
Johny Isla Cuadrado a \\ Markus Reindel ${ }^{\mathrm{b}}$
}

\begin{abstract}
Resumen
Las evidencias arqueológicas documentadas en los valles de Palpa indican que al final del Formativo, en un lapso de tiempo comprendido entre el final del desarrollo Paracas y el inicio de Nasca, hubo un periodo de transición en donde ocurrieron cambios importantes en el proceso sociocultural que afectaron los aparentes lazos de continuidad entre ambas formaciones sociales. Este lapso de tiempo, conocido como Proto-Nasca o Nasca Inicial en la cuenca del río Grande, está relacionado con la repentina aparición de elementos asociados a Topará, un grupo social que parece haber ejercido el control politico y religioso de la costa sur al final del Periodo Formativo, configurando un nuevo escenario en el que se conjugaron rasgos tipicos de los paracas y los nasca. En este sentido, la discusión se enfoca en las implicancias que tuvo Topará en este proceso de transición, en el cual, al parecer, solamente los denominados textiles "Paracas» de la fase Necrópolis representan los lazos de continuidad entre ambas formaciones sociales. Esta continuidad evidentemente tuvo un fuerte trasfondo ideologico y religioso.

En este manuscrito se expondrán las evidencias arqueológicas — patrones de asentamiento, geoglifos, petroglifos, cerámica, etc.—, que configuraron este nuevo escenario en los valles de Palpa, en base a las cuales se discutirán las características que tuvo la transición Paracas-Nasca en la cuenca del rio Grande y sus implicancias en el contexto regional.
\end{abstract}

Palabras claves: Paracas, Nasca, Topará, transición, rio Grande, valles de Palpa y Nazca.

\section{Abstract}

\section{THE PARACAS-NASCA TRANSITION IN THE PALPA VALLEYS}

Archaeological evidence documented in the Palpa valleys indicates that at the end of the Formative period, between the decline of the Paracas and the beginning of the Nasca, there was transition period in which important changes took place in the sociocultural process that affected the apparent links of continuity between both sociopolitical entities. This time period, known as Proto-Nasca or Initial Nasca in the Rio Grande basin, is closely related to the sudden appearance of elements related with the Topara, a social group which seems to have exercised political and religious control of the southern coast at the end of the Formative period, configuring a new scenario in which typical traits of the Paracas and Nasca were combined. In this sense, the discussion focuses on the implications of the Topara had in this transition process, in which only the so-called "Paracas" textiles of the Necrópolis phase represent the ties of continuity between both sociopolitical entities. This continuity evidently had strong religious and ideological connotations.

In this paper the archaeological evidences (settlement patterns, geoglyphs, petroglyphs, pottery, etc.) that set this new stage in the valleys of Palpa will be presented, on the basis of which we discuss the characteristics that the Paracas-Nasca transition had in the Rio Grande basin and its implications in the regional context.

Keywords: Paracas, Nasca, Topará, transition, rio Grande, Palpa and Nasca valleys.

a ANDES: Centro de Investigación para la Arqueología y el Desarrollo

Correo electrónico: isla.nasca@gmail.com

b KAAK: Comisión de Arqueología para Culturas No Europeas del Instituto de Arqueológico Alemán (DAI)

Correo electrónico: markus.reindel@dainst.de 


\section{Introducción}

La arqueología de la costa sur del Perú es bien conocida por el desarrollo de dos de las formaciones sociales más importantes del área andina: Paracas y Nasca. Dos grupos sociales de alcance regional que lograron altos niveles de desarrollo y complejidad social, que en el caso de los paracas se observa especialmente en sus grandes monumentos arquitectónicos y en sus elaborados textiles con bordados multicolores; mientras que, en el caso de los nasca, se observa en sus acueductos, sus geoglifos y su fina cerámica polícroma. Aunque los estudios sobre ambas sociedades datan desde inicios del siglo pasado, solo en los últimos años, con el desarrollo de numerosos proyectos arqueológicos orientados al estudio de los asentamientos, las costumbres funerarias y otros aspectos de la vida cotidiana, se ha renovado e intensificado el interés en tener un mejor entendimiento de ambas sociedades (Massey 1986; Silverman 1993; Carmichael 1995; De Leonardis 1997; Peters 1997; Reindel et al. 1999; Schreiber y Lancho 2003; Vaughn 2004). Justamente, los resultados de estos estudios están brindando una nueva perspectiva sobre el desarrollo que tuvieron los paracas y los nasca, más allá del enfoque estilístico que predominaba en los estudios previos.

A la gran tarea que implica entender el desarrollo de ambas sociedades, se agrega el problema de conocer y entender mejor cómo fue el proceso de transición de la una hacia la otra. En palabras sencillas, se trata de saber si fue una transición gradual o fue provocada por otros factores, ya sea internos o externos. En este sentido, en los últimos años también se ha incrementado el interés por entender cómo fue la transición de Paracas a Nasca y cuáles fueron sus implicancias en el posterior desarrollo de la cultura Nasca (Domenici 1994; Orefici 1996; Peters 1997; Vaughn y Van Gijseghem 2007; Tinteroff 2008; Llanos 2008) ${ }^{1}$. Teniendo en cuenta estos aspectos, en este artículo se presenta un enfoque de esta transición en los valles de Palpa, motivados por el descubrimiento de numerosas y variadas evidencias arqueológicas pertenecientes a este lapso de tiempo, las cuales plantean una nueva perspectiva para entender este proceso.

Partiendo de un contexto más amplio, se debe señalar que la mayoría de los estudios en la costa sur indican que, al notable desarrollo alcanzado por los paracas en los valles de Ica, Pisco y Chincha, le siguió un floreciente desarrollo de los nasca en los valles de Ica, Palpa y Nazca (Fig. 1). Así mismo, se indica que entre ambas hubo un período de transición que, según los estudios previos, fue gradual y sujeto a cambios de carácter puramente estilístico. Dicho de otro modo, en base a las secuencias de cronología relativa apoyadas en la cerámica Paracas y Nasca (Rowe 1958; 1960; Menzel et al. 1964; Pezzia 1968), el estilo Nasca fue reconocido como el desarrollo continuo del estilo Paracas, a partir de la comparación estilística de los motivos iconográficos plasmados en los tejidos y la cerámica de ambas formaciones sociales (Lanning 1960; Menzel et al. 1964; Dwyer 1971; Paul 1982).

Desde esta perspectiva, la transición de Paracas a Nasca se podía observar en los cambios formales y estilísticos ocurridos en la producción textil y alfarera de ambas sociedades, en las cuales se podía ver los grados de evolución artística y las transformaciones tecnológicas. De este modo, se demostraba la ausencia de un rompimiento estilístico y se dejaba implícito que ambas eran parte de una misma tradición cultural en la que había fuertes elementos de continuidad (Menzel et al. 1964: 251). En tal sentido, los cambios tecnológicos operados en la producción alfarera fueron atribuidos a la influencia de la «tradición» Topará, específicamente de sus fases Jahuay 3 y Chongos, las cuales cronológicamente son contemporáneas con las fases Ocucaje 10, Nasca 1 y Nasca 2. Los lazos culturales entre Paracas, Topará y Nasca fueron enfocados inicialmente por Dororthy Menzel (1971: 57-62), luego esbozados más ampliamente por Ann Peters (1997: 9-20) y más recientemente por Vanessa Tinteroff (2008).

La tradición Topará, como se sabe, tuvo su principal centro de desarrollo en los valles de Chincha y Pisco (Lanning 1960, Menzel 1971 y Wallace 1986), desde donde luego se extendió al valle de Ica, influyendo de este modo en la tradición estilística Paracas y generando las innovaciones tecnológicas que luego dieron origen al estilo Nasca (Menzel et al. 1964: 211-213, 257, 259; 
Figura 1. Mapa de la Costa Sur del Perú con ubicación de la cuenca del río Grande, la cual está integrada por los valles de Palpa y Nazca (Mapa elaborado por los autores).

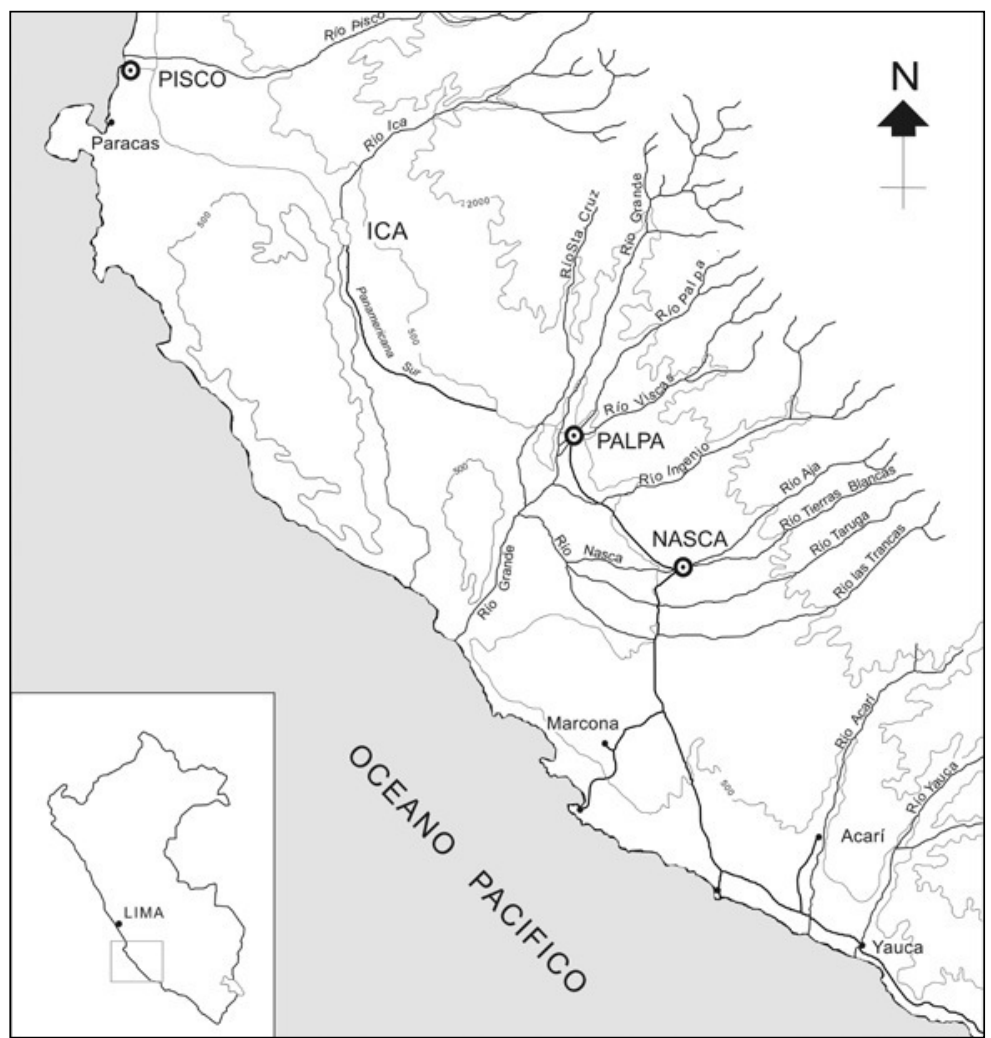

Wallace 1985: 92-93; Wallace 1986: 39; Peters 1997: 894). Desde esta perspectiva, se estima que la transición de Paracas a Nasca se dio en el contexto de una evolución natural, la cual, no obstante, fue afectada por la influencia de los Topará.

Como se puede ver hasta aquí, la transición Paracas-Nasca en la costa sur ha sido planteada y entendida desde una perspectiva puramente estilística, asumiendo que las secuencias de cronología cerámica se repiten por igual en todos los valles y dejando de lado otros aspectos de la cultura material, entre los que habría que mencionar, por ejemplo: el estudio de los asentamientos, los patrones funerarios, el manejo del territorio, etc. Si bien la falta de contextos estratigráficos sigue siendo un problema a resolver, pensamos que, en oposición a ello, el análisis conjunto de los diversos rasgos arqueológicos y su distribución en un espacio determinado, puede ser de gran utilidad para abordar el tema (ver Peters 1997; Tinteroff 2008).

Teniendo en cuenta esto, las evidencias arqueológicas documentadas en los últimos años en los valles de Palpa nos ofrecen una buena posibilidad para analizar la transición de Paracas a Nasca por varias razones. En principio, porque a diferencia de otros valles de la costa sur, en dichos valles se ha registrado y documentado una larga historia cultural, que empezó mucho antes del desarrollo de los paracas y continuó hasta mucho después del final de los nasca. Además, en el caso del período de transición entre ambas, en Palpa se han registrado sitios que fueron ocupados solo en ese lapso de tiempo (Reindel 2009; Isla 2010). Esto nos ha permitido identificar los rasgos culturales de cada período y fijar su posición mediante excavaciones estratigráficas, cronología relativa y fechados absolutos.

Así, ahora sabemos que, en los valles de Palpa, como también en aquellos de Nazca, hubo una importante ocupación Paracas que no parece haber sido muy diferente a la que había en el valle de Ica y otros de más al norte (Reindel e Isla 2006; Isla y Reindel 2007), los cuales se consideran como 
el área nuclear del desarrollo de los paracas. Para el caso de los nasca, se sabe que la cuenca del río Grande - integrada por nueve valles_-, fue el área nuclear de su desarrollo, donde sus evidencias se pueden ver por todas partes. En este contexto, las investigaciones en Palpa nos han permitido documentar que, entre el desarrollo de ambas sociedades, hubo una ocupación continua que estuvo marcada por cambios importantes, que se reflejan principalmente en un notable incremento en el número de habitantes y por tanto en el número de asentamientos. Estos cambios, a su vez, estuvieron acompañados por un nuevo estilo de cerámica que, según sus rasgos formales y estilísticos, muestran fuertes relaciones con el estilo Topará, así como por un aumento en la producción de petroglifos y geoglifos en la zona.

Desde esta perspectiva, si bien se puede decir que la transición de Paracas a Nasca en la costa sur representa, en varios aspectos, un período de gradual transición de la precedente época Paracas Tardío a la siguiente época Nasca Temprano; las evidencias documentadas en los valles de Palpa indican que esta transición parece que no fue ni tan gradual ni tan natural como tradicionalmente se piensa, sino que estuvo marcada por profundos cambios en la estructura social, en la organización de los asentamientos y por ende también en la cultura material de ese tiempo.

Estos cambios, desde nuestra perspectiva, fueron promovidos por el surgimiento de nuevas élites políticas relacionadas con la tradición Topará, la cual, desde nuestro punto de vista, fue la que auspició los cambios ocurridos en este período de transición de Paracas a Nasca en los valles de Palpa y Nasca, conservando algunos rasgos culturales que permiten ver entre ambas un evidente lazo de continuidad ${ }^{2}$. Esto es especialmente visible en los íconos religiosos plasmados en los textiles bordados de la fase Necrópolis, que luego se trasladaron a la cerámica pintada del estilo Nasca. Un escenario similar también ha sido planteado antes para el valle de Ica (Massey 1986).

Teniendo en cuenta estos aspectos, seguidamente presentamos las evidencias documentadas en los valles de Palpa, las cuales se han obtenido en los últimos años en base a largos e intensos trabajos de campo: prospecciones arqueológicas, excavaciones de prueba, etc. En este sentido, también se presentan los resultados del análisis del patrón de asentamiento, los cuales se exponen en relación con los resultados obtenidos mediante las investigaciones del paleoambiente, de tal manera que se pueda entender mejor las condiciones medioambientales en las que ocurrió el proceso de asentamiento en los valles de Palpa.

Desde esta perspectiva también se discutirán aspectos relacionados con la arquitectura y la cerámica para identificar mejor los rasgos que caracterizan la transición de Paracas a Nasca. Asimismo, aunque las evidencias todavía son escasas, se esbozan los rasgos principales que presentan las costumbres mortuorias de la época. Lo mismo haremos con los petroglifos y geoglifos registrados en los valles de Palpa, para explicar la importancia de estos en esta época de transición. Varios fechados de radiocarbono nos permitirán ubicar este período en la cronología general de la región. Finalmente, se concluye con algunos planteamientos sobre las características que tuvo la transición de Paracas a Nasca en los valles de Palpa, señalando sus implicancias en el contexto regional.

\section{Contexto geográfico y cultural}

Los datos y resultados que se presentan aquí provienen de las investigaciones interdisciplinarias que, por más de 15 años, se realizaron en los valles de Palpa, en la costa y sierra sur del Perú. Las investigaciones se hicieron en el marco del Proyecto Arqueológico Nasca-Palpa, bajo la dirección de los autores de este artículo. En el curso de estas, por primera vez se ha llegado a registrar y documentar las evidencias arqueológicas que testimonian la existencia de un rico y variado proceso cultural, el cual cubre más de 5,000 años de historia prehispánica en los valles de Palpa (Reindel 2009; Isla 2010). En este largo proceso, evidentemente, destaca el notable desarrollo que tuvieron las culturas Paracas y Nasca, dos de las formaciones sociales más importantes del área andina, las cuales justamente han recibido la mayor atención en nuestros estudios. 
Los valles de Palpa se consideran oasis formados por los ríos Santa Cruz, Grande, Palpa y Viscas, los cuales se encuentran en la parte norte de la cuenca del río Grande de Nasca ${ }^{3}$. Dicha cuenca comprende un extenso territorio que incluye una gran planicie desértica y la vertiente occidental de los Andes que, por intervalos, es interrumpido por pequeños valles que descienden desde la cordillera de los Andes hasta el Océano Pacífico, por los cuales discurren los ríos más secos de la costa peruana. Estos ríos tienen un régimen de agua irregular que, solo en los meses de verano, cuando ocurren las lluvias estacionales en la sierra, transportan abundante agua que sirve para convertir el desolado paisaje del desierto en fértiles oasis.

Debido a la peculiar topografía de la región y a la característica de sus ríos, los valles de Palpa y Nasca, a diferencia de los más amplios y mejor irrigados de la costa central y norte del Perú, se encuentran tierra adentro, lejos del mar, formando verdaderos fértiles oasis ubicados al pie de los Andes, en donde se ha registrado un largo y complejo desarrollo cultural (ver cuadro cronológico en Unkel et al. 2012: 2299; fig. 2).

El área principal de las investigaciones del Proyecto Arqueológico Nasca-Palpa se localiza en la parte norte de la cuenca del río Grande, alrededor de la ciudad de Palpa, en una zona que va desde la confluencia de los ríos Grande e Ingenio y el curso medio de los ríos Grande, Palpa y Viscas, desde los 200 hasta los 1600-1800 metros sobre el nivel del mar (Fig. 2). En los últimos años, desde el 2006 al 2014, las investigaciones del proyecto Nasca-Palpa se han extendido por toda la zona yunga — la yunga desértica — hasta llegar a la sierra y la puna misma, arriba de los 4350 m.s.n.m. ${ }^{4}$, en donde también se han registrado diversas evidencias de ocupaciones culturales correspondientes a todos los períodos de tiempo, en especial aquellas relacionadas con las culturas Paracas, Nasca e Ica/Chincha, cuyo ámbito de desarrollo tradicionalmente se piensa que se limitaba a la costa (Reindel e Isla 2013, Isla y Reindel 2017). ${ }^{5}$.

En este sentido, las investigaciones realizadas en los valles de Palpa indican que la primera ocupación prehispánica en la región data del período Arcaico Medio (Unkel et al. 2007, 2012). Después de un vacío de casi 1500 años todavía por llenar, las evidencias indican que la zona fue ocupada más intensivamente durante el Período Inicial (1500-800 a.C.), cuando la región gozaba de condiciones climáticas favorables (Reindel e Isla 2009; Gorbahn 2013). Durante el Formativo Medio y Tardío, en relación con el desarrollo Paracas (800-200 a.C.), los valles de Palpa fueron más densamente poblados y prácticamente se ocuparon todos los pisos ecológicos desde el litoral hasta la puna. En este contexto, uno de los picos más altos de poblamiento se alcanzó al final del Formativo, en relación con la etapa de transición de Paracas a Nasca (200 a.C.-50 d.C.). Durante el desarrollo Nasca (50-650 d.C.) la región experimentó un notable florecimiento cultural, seguido de un repentino decaimiento en la época Nasca Tardío provocado por una fase de extrema aridez (Eitel et al. 2005; Mächtle y Eitel 2013), la cual se prolongó hasta el final del primer milenio de nuestra era. Después de mantenerse poco poblada durante el Horizonte Medio (650-1000 d.C.), un aumento en las condiciones de humedad condujo a un re-poblamiento de la región durante el Período Intermedio Tardío, en relación con el desarrollo Ica-Chincha (1000-1470 d.C.). Finalmente, los inka (1470-1532 d.C.) llegaron a controlar la región justo cuando empezaba una nueva fase de aridez que persiste hasta la actualidad.

Teniendo en cuenta este panorama del proceso cultural documentado en Palpa, el período de transición de Paracas a Nasca resulta de especial interés porque representa una etapa de experimentación y cambio, la cual constituyó el preludio de una mayor transformación sociopolítica en los valles de Palpa y Nasca y, en general, en toda la costa sur del Perú.

\section{Los trabajos de campo}

Las investigaciones en Palpa han comprendido intensos trabajos de campo, entre los que destaca la prospección arqueológica realizada en los valles de los ríos Grande, Palpa y Viscas, en los cuales 


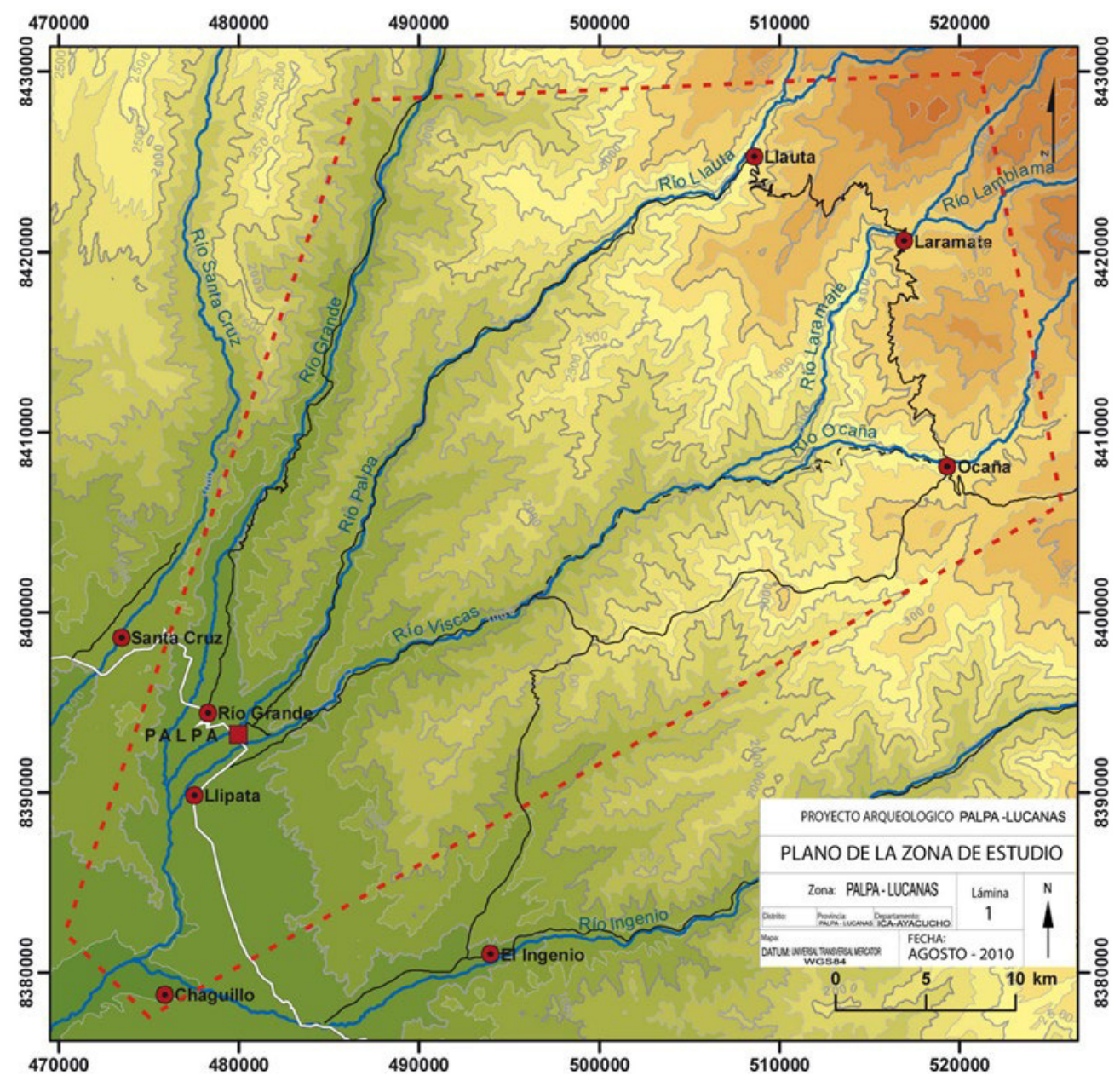

Figura 2. Mapa de los valles de Palpa, en la parte norte de la cuenca del rio Grande, los cuales conforman el área nuclear de las investigaciones del Proyecto Nasca-Palpa (Mapa elaborado por los autores).

se han hecho recorridos a pie cubriendo sus dos lados, así como las zonas intermedias entre ellos. Además, en los alrededores de la ciudad de Palpa la prospección también ha comprendido las laderas y mesetas desérticas adyacentes a los valles (Reindel et al. 1999; Isla y Reindel 2005). En este sentido, la prospección por cada uno de estos valles ha cubierto una distancia lineal de más de 40 kilómetros, partiendo desde la confluencia de los ríos Ingenio y Grande hasta el sector de El Palmar, por el valle del río Grande, Pucurí por el valle de Palpa y Huayrana por el valle de Viscas. De este modo, en varias temporadas de campo — 1997, 2000, 2001, 2003, 2007 y 2009— se llegó a cubrir un área de más de 800 kilómetros cuadrados, los cuales se encuentran mayormente en la costa y la yunga desértica.

Durante los trabajos de prospección en la zona de la costa y yunga, entre los 250 y los 1600-1800 m.s.n.m., hemos identificado y registrado más de 790 sitios arqueológicos pertenecientes a todos las épocas y períodos de tiempo. Como sitios arqueológicos se han considerado los asentamientos (sitios de habitación, productivos y ceremoniales), los cementerios, los geoglifos y petroglifos, las estructuras funerarias y otros rasgos menores de especial significado como espacios abiertos, altares o plataformas de significado ritual. Adicionalmente se han registrado las terrazas agrícolas, los canales y caminos prehispánicos. 
Además de los trabajos de reconocimiento y prospección arqueológica efectuados en los valles de Palpa, se han realizado excavaciones en área y excavaciones de prueba, en varios sitios de casi todos los períodos de tiempo, de manera especial en aquellos pertenecientes a Paracas y Nasca. En este caso, es importante resaltar las excavaciones en área realizadas en los sitios de Jauranga, Los Molinos y La Muña (Reindel e Isla 2001, 2006; Isla y Reindel 2007; ver también Isla et al. 2003).

En este contexto, conviene indicar que los datos y evidencias relacionadas con el período de transición Paracas-Nasca, también conocido como Proto-Nasca o Nasca Inicial en la cuenca del río Grande, básicamente provienen de los trabajos de prospección, de las observaciones de superficie y de excavaciones restringidas realizadas en algunos pocos sitios. No obstante, este período de transición, que en nuestra base de datos está representado por tener el más alto número de sitios arqueológicos a lo largo del tiempo, muchos de ellos con petroglifos y otros con geoglifos, resulta de especial importancia para entender el sucesivo desarrollo que tuvo la sociedad Nasca en la región.

\section{Los asentamientos}

Durante los trabajos de prospección realizados en los primeros años en los valles de Palpa, entre la costa — alrededor de la ciudad de Palpa — y la yunga — bajo los 1800/1600 msnm—, se han registrado más de 790 sitios arqueológicos pertenecientes a todos los períodos de tiempo, de los cuales 553 pueden ser definidos claramente como asentamientos o lugares de vivienda ${ }^{6}$. Los otros sitios están representados por cementerios, plataformas o espacios abiertos de uso público o ceremonial, sitios con petroglifos, sitios con geoglifos, terrazas agrícolas, canales antiguos, etc.

La mayoría de los asentamientos o lugares de vivienda de este tiempo corresponden a sitios de habitación, en los cuales con frecuencia también hay áreas de enterramiento o cementerios y en menor cantidad también petroglifos y geoglifos. En este sentido, se debe indicar que, aunque los sitios pueden tener un componente solamente habitacional, no es raro encontrar sitios que presentan dos o más componentes. Asimismo, entre los asentamientos se distinguen varios sitios que además de vivienda o función doméstica también presentan construcciones o rasgos que indican una función pública y ceremonial. Esta clase de asentamientos son frecuentes en relación con el desarrollo de los nasca pero ya se pueden percibir desde este tiempo.

Los datos indican que, de los 553 sitios o asentamientos registrados en los valles de Palpa, en 224 de ellos se han identificado evidencias de ocupación del período de transición de Paracas a Nasca (Fig. 3). Los sitios de este tiempo son fáciles de identificar debido a que conforman poblados bien delimitados, donde se observa una gran cantidad de terrazas y recintos de habitación que muestran un patrón bastante concentrado, además de cerámica distintiva en la superficie. Asimismo, los sitios se localizan sobre laderas y colinas que están un tanto arriba con relación al borde de los valles.

La mayoría de estos poblados corresponden a sitios de habitación, entre los cuales se puede distinguir hasta tres principales tipos de asentamiento según el tamaño, el número de recintos y la variación en sus componentes arquitectónicos. Así, tenemos los simples caseríos conformados por solo unas pocas unidades de vivienda; las aldeas o pequeños poblados que incluyen un mayor número de viviendas y espacios comunales; y los grandes poblados con una gran cantidad de viviendas, espacios comunales y algunas estructuras o espacios abiertos de posible función pública (Fig. 4). Si bien la diferencia entre estos tres tipos de sitios está marcada por los parámetros antes indicados, otros tipos de sitios más se pueden distinguir si se tiene en cuenta su ubicación, apariencia y organización espacial de los mismos (ver Silverman 2002: 58), así como por la presencia, ausencia o combinación de otros componentes arqueológicos, lo cual aquí no es relevante mencionar.

Independientemente del tamaño de los sitios, la mayoría de los asentamientos de este tiempo se caracterizan por la presencia masiva de terrazas de habitación, las cuales están construidas en base a muros de contención hechos con piedras de campo y piedras canteadas, sobre los cuales se fijaban sencillas paredes de quincha sostenidas con postes de sauce o huarango. Por lo general, los muros 


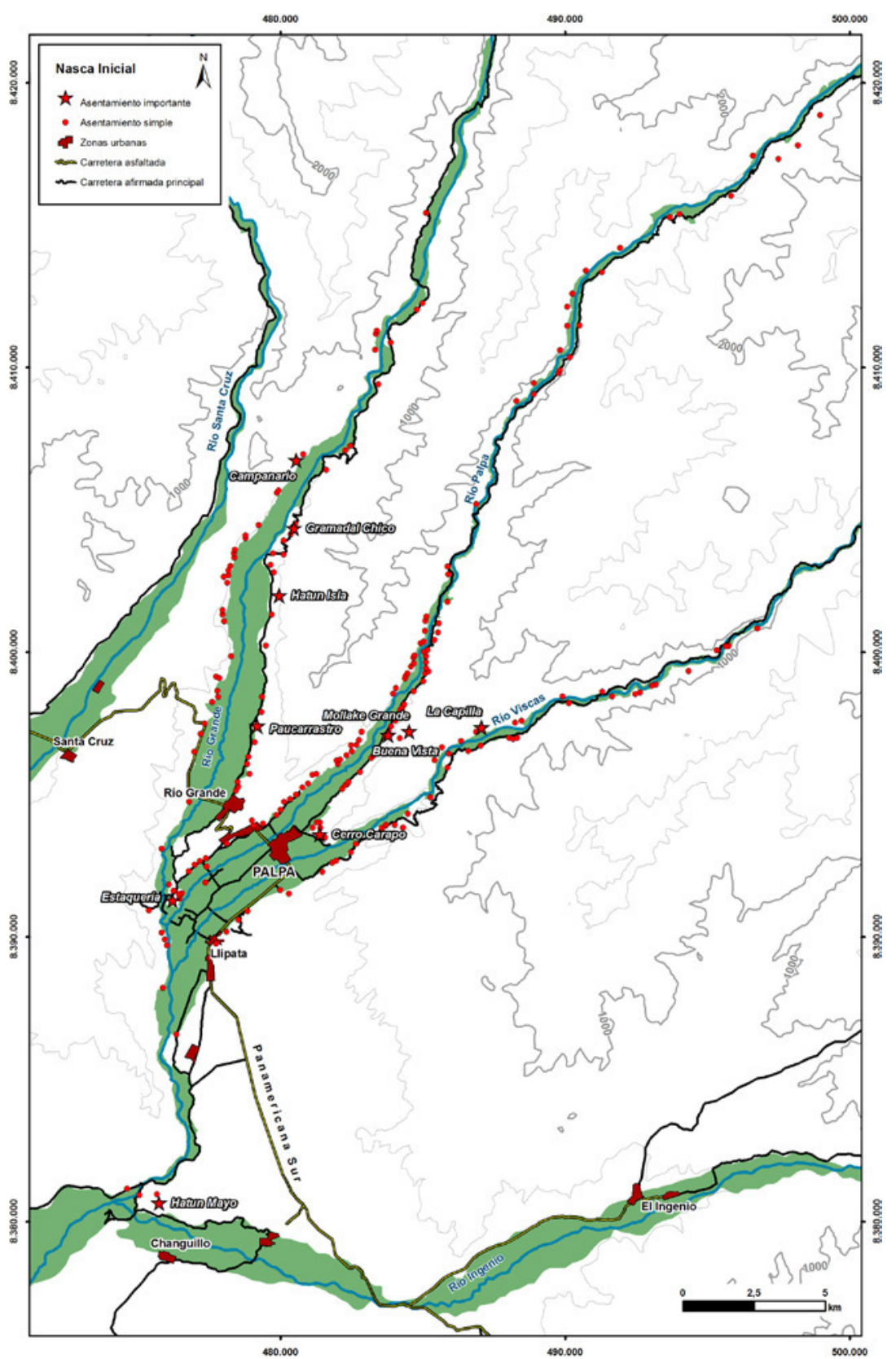

Figura 3. Mapa de los valles de los rios Grande, Palpa y Viscas, donde se muestra la ubicación de los sitios — solo los asentamientos_-pertenecientes a la época de transición Paracas-Nasca (Mapa elaborado por los autores).

de contención de las terrazas están formadas por una hilera de piedras que conservan entre 0.5 y 1 metro de altura promedio. Este es el sistema constructivo típico, que fue adaptado al contorno de las laderas y colinas que bordean los valles, presentando perfiles escalonados que usualmente están mirando hacia el valle. Raramente los sitios de habitación fueron establecidos sobre zonas escarpadas o terrazas naturales y tampoco en zonas planas cerca del borde de los valles. Uno de los pocos casos está representado por el sitio de Estaquería, ubicado cerca de la confluencia de los valles 


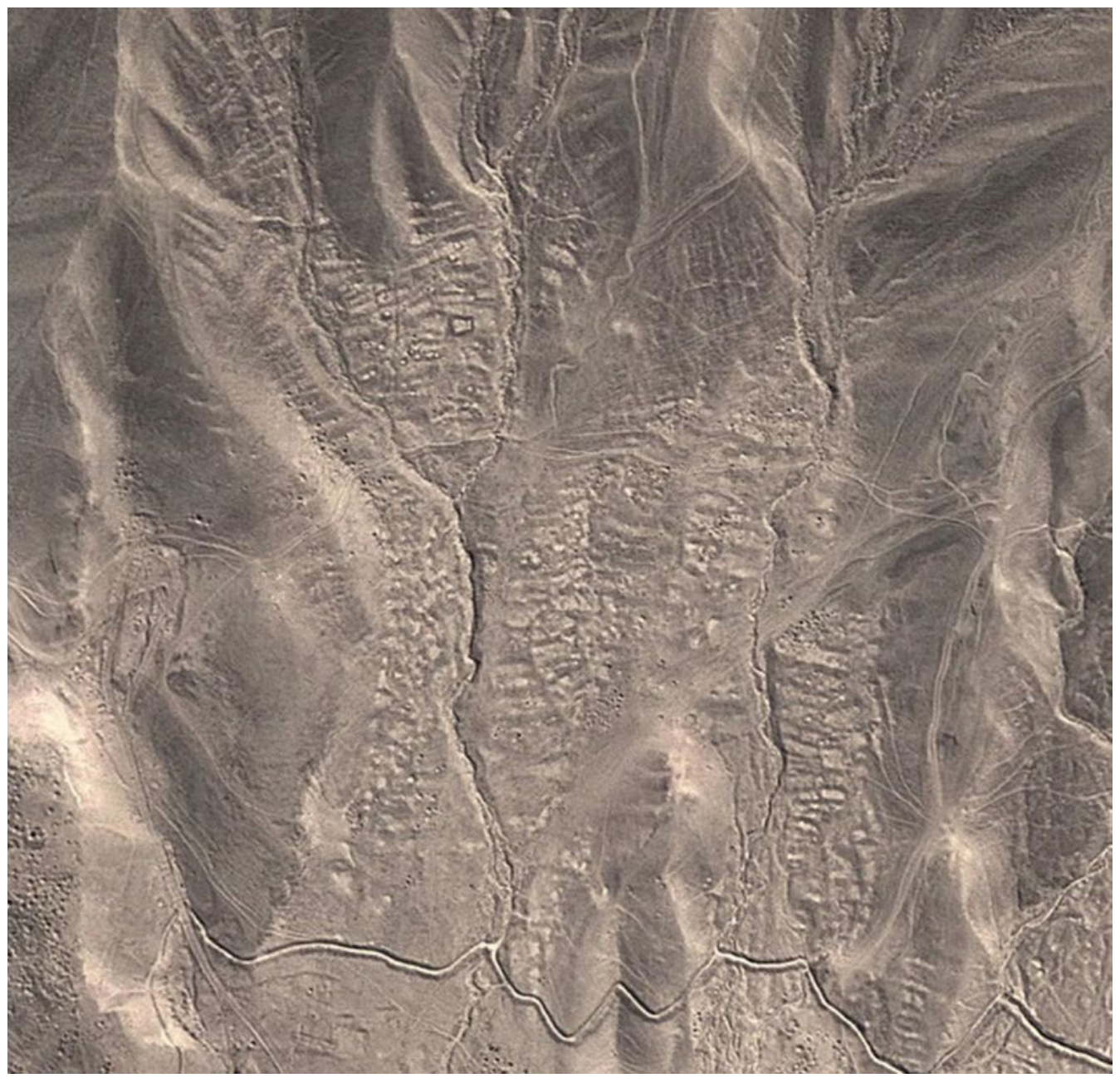

Figura 4. Foto satelital de la parte central de Belén Alto (sitio PAP-1120), localizado cerca de la confluencia de los valles de Ingenio y rio Grande, en una zona con grandes campos de cultivo y mayor disponibilidad de agua (Fuente Google Earth 2013).

de Palpa y río Grande, en donde los recintos de piedra y quincha se han establecido en zonas casi planas y suaves lomas que se encuentran cerca del borde del valle.

En algunos sitios, especialmente en aquellos más grandes y que parecen haber sido los centros más importantes de esta época, además de las terrazas de habitación también se observan recintos de diferentes tamaños de planta circular, ovalada, rectangular y otros de contorno irregular. Estas construcciones están hechas con una o doble hilera de piedras de diferente tamaño, las cuales pueden estar en una amplia terraza o sobre laderas. Estos recintos se pueden interpretar como espacios de uso comunal. En estos mismos sitios también se pueden ver espacios de uso público o ceremonial conformados por espacios abiertos, plataformas, pequeños montículos o áreas limpias y delimitadas en la cima de las colinas. Tampoco es raro observar pequeńas estructuras circulares de piedras o cistas revestidas con piedras que parecen haber funcionado como silos o depósitos. Finalmente, en relación con algunos de estos sitios también se encuentran pozos huaqueados que claramente indican la existencia de cementerios además de petroglifos y geoglifos.

Uno de los poblados más grandes que, por sus características y rasgos asociados, puede ayudar a entender mejor cómo eran los sitios de ese tiempo en los valles de Palpa es Carapo. Este sitio ocupa 


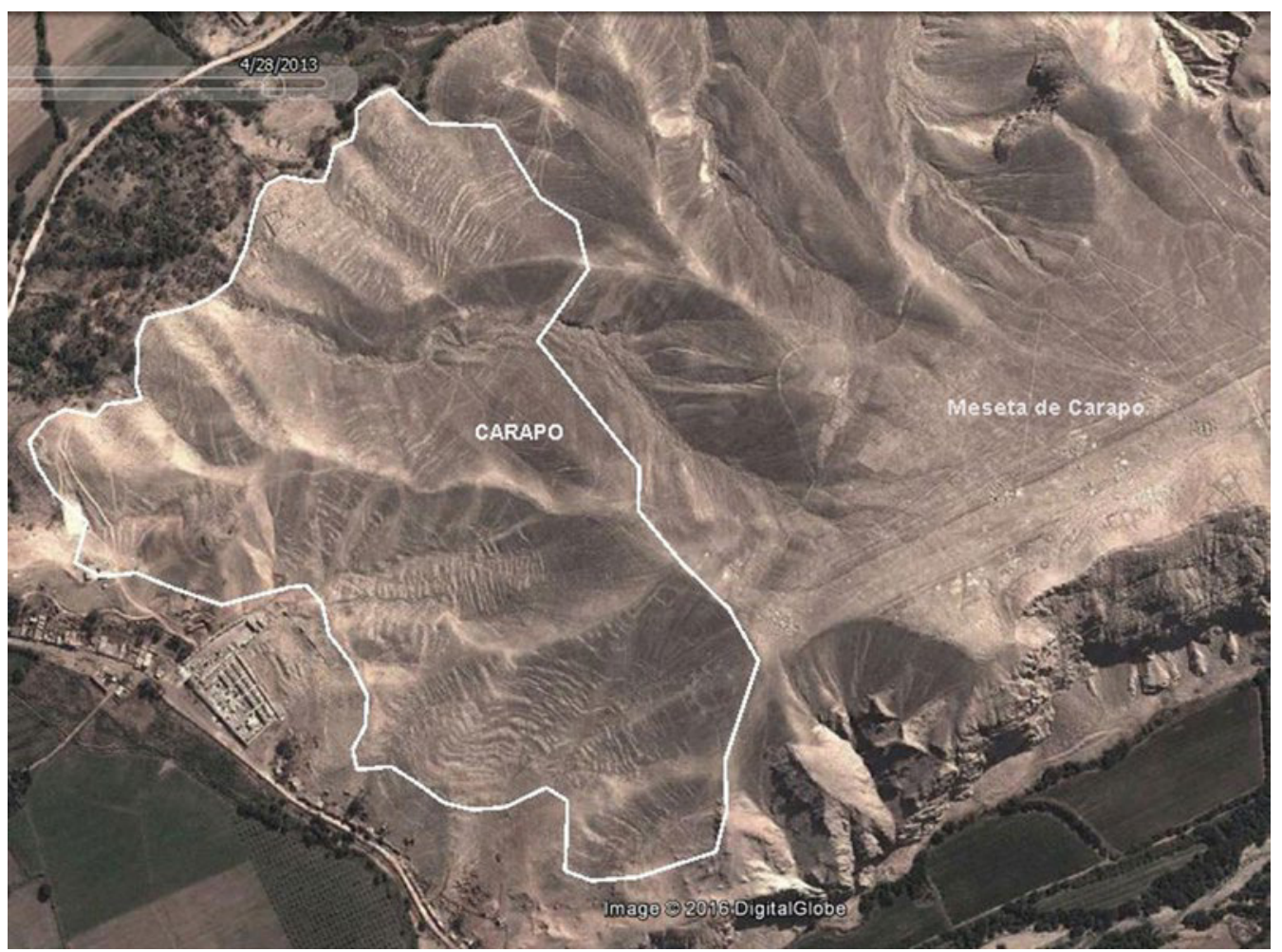

Figura 5. Foto satelital del sitio de Carapo, localizado en la confluencia de los valles de Palpa y Viscas, en donde se pueden ver los varios conjuntos de terrazas de habitación que componen el sitio (Fuente Google Earth 2013).

un espacio de más de 20 hectáreas y se encuentra ubicado estratégicamente justo en la confluencia los valles de Palpa y Viscas, ocupando casi toda la ladera Noroeste, Oeste y Sudoeste de la planicie y de los cerros que separan ambos valles (Fig. 5). Sobre la meseta que se encuentra inmediatamente arriba del sitio, por su lado Este, se encuentra un grupo de geoglifos de filiación Nasca, algunos de los cuales parecen que fueron trazados durante este tiempo y luego se ampliaron en la fase Nasca 2.

Carapo es un sitio típico de este tiempo, el cual comprende una gran cantidad de terrazas de habitación distribuidas en grupos separados por pequeñas quebradas, las cuales se extienden desde casi el borde del valle hasta las partes más altas de la ladera. En forma más aglutinada o dispersa, las terrazas fueron dispuestas en forma escalonada siguiendo la pendiente de la ladera. Todas las terrazas están construidas con muros de contención hechos con piedras de campo, las cuales servían para sostener construcciones simples de quincha. Restos de paredes de quincha y postes todavía se observan en varias partes del sitio, así como también pozos huaqueados con restos funerarios dispersos, lo que indica también la existencia de áreas de enterramiento o cementerios. Justamente en Carapo, en una de las laderas del lado sudoeste, se llegó a registrar un pozo en donde había un entierro perteneciente a esta época que se describe más adelante.

Si bien en algunas partes se reconocen algunas diferencias en el tamaño de las terrazas o subdivisiones internas, en general, no se han observado recintos más grandes u otras construcciones más elaboradas o complejas ${ }^{7}$. La ausencia de esta clase de construcciones en Carapo estaría indicando un bajo grado de estructuración interna, lo cual evidentemente estaría en relación con la población que vivía allí. No obstante, se debe señalar que en la parte baja y sudoeste del sitio, todavía se observan los restos de grandes recintos y espacios abiertos que al parecer formaban parte de construcciones más elaboradas, lo cual le otorgaría un mayor estatus en la jerarquía de sitios $^{8}$. Esto debe 
ser comprobado con futuras excavaciones en esa parte del sitio, lo cual estaría más de acorde con el tamaño y la ubicación que tenía Carapo en relación con otros sitios contemporáneos. La jerarquía de los asentamientos de esta época debe ser analizada con excavaciones en ellos.

Otros sitios que presentan las mismas características observadas en Carapo son Campanario, Gramadal Chico, Alto La Isla y Paucarastro en el valle del río Grande, Estaquería y Buena Vista en el valle de Palpa, los cuales parecen haber sido los centros principales de la época. Un sitio adicional que seguramente fue uno de los más grandes e importantes de la época es Belén Alto (Fig. 4), el cual ocupa diversas laderas y lomadas del lado Sudoeste de los cerros que se encuentran en la margen derecha del valle de Ingenio, poco antes de la confluencia de este con el valle del río Grande. Este sitio ha sido registrado por Silverman (2002: 67-68) y, como ella sostiene, la gran cantidad de construcciones existentes en el sitio seguramente fue favorecida por su ubicación en una zona de fácil acceso a los recursos del valle, donde hay amplios campos de cultivo y agua casi durante todo el año?

\section{Patrones de asentamiento}

Como ya se dijo antes, 224 de los 553 sitios registrados en los valles de Palpa pertenecen al período de transición de Paracas a Nasca. Este número representa casi el doble de asentamientos con respecto a la época Paracas Tardío (fases Ocucaje 8 y Ocucaje 9), lo que claramente está indicando que en este tiempo hubo un notable incremento en la densidad poblacional de dichos valles ${ }^{10}$. Sin embargo, esta situación cambió nuevamente hacia la época Nasca Temprano (fases Nasca 2 y Nasca 3), cuando hubo una disminución en el número de sitios y se observa el abandono de la mayoría de poblados de la época de transición.

En principio, el análisis de los patrones de asentamiento indica que durante este tiempo hubo una clara preferencia por fijar el principal centro de asentamiento valle abajo, cerca de las zonas planas y con mayores terrenos de cultivo, las cuales se encuentran en la parte baja del valle del río Grande (entre los sectores de Molinos y Parasmarca) y cerca de la confluencia de los ríos Grande, Palpa y Viscas (alrededor de la amplia planicie formada por la confluencia de los tres valles). Esto es claramente diferente con respecto a lo que sucedía en la época Paracas Tardío, cuando la mayor concentración de los asentamientos se localizaba en la parte media y media-alta de los valles. Este movimiento continuó durante la época Nasca Temprano, cuando la mayoría de asentamientos fueron establecidos alrededor de las zonas planas antes indicadas, siendo distribuidos regularmente a lo largo del borde de los valles. Desde esta perspectiva, el cambio en la ubicación de los principales centros poblados resulta todavía más evidente si consideramos los focos de asentamiento de cada tiempo. Así, mientras que en la época Paracas Tardío estos centros están concentrados en la parte media de los valles, en la época de transición estos se mueven hacia las partes bajas y planas. Por último, en la época Nasca Temprano los principales centros están localizados alrededor de las zonas planas y con mayores tierras disponibles para la agricultura.

No obstante, los asentamientos de la época de transición ocupan laderas altas y colinas que se encuentran un poco alejadas del borde del valle y, casi siempre, sobre el nivel que ocupan los asentamientos Paracas Tardío y Nasca Temprano. Esto es más evidente en la yunga desértica, donde los sitios ocupan la cima de colinas o laderas altas que se encuentran bastante lejos del fondo de los valles. En este sentido, se debe decir que en muy pocos casos se encuentran sitios Paracas en ubicaciones altas y alejadas del valle, situación que por lo demás es totalmente diferente en los sitios de filiación Nasca.

Por otro lado, los estudios del paleoclima realizados en los valles de Palpa indican que a lo largo del tiempo hubo una estrecha relación entre los cambios climáticos y los cambios en los patrones de asentamiento. En este sentido, los estudios geoarqueológicos han develado más de 9,000 años de historia paleoclimática, lo cual ha permitido detectar los cambios climáticos ocurridos en el tiempo y entender su impacto en las formaciones sociales prehispánicas establecidas en la región (Eitel et al. 2005; Eitel y Mächtle 2009; Mächtle y Eitel 2013). Dichos estudios han puesto en evidencia 
que hacia finales del Período Formativo la región fue afectada por la intensificación de un proceso de aridez que culminó en un período de extrema aridez al final del desarrollo de los nasca. Desde esta perspectiva, resulta evidente que las condiciones de mayor humedad existentes antes de este proceso favorecieron la ocupación humana de los valles de Palpa y Nazca. Si bien durante la época de transición de Paracas a Nasca la aridez aumentó, se puede decir que la región todavía mantenía buenas condiciones de humedad. Por lo tanto, no es difícil de imaginar que en ese tiempo los ríos tenían más agua y por tanto había las condiciones para mantener una economía estable basada en la producción agrícola ${ }^{11}$.

En este contexto, resulta importante remarcar que además de las condiciones climáticas favorables, durante el período de transición de Paracas a Nasca hubo, a nuestro entender, un factor externo que propició el repentino incremento de sitios y el consecuente aumento de la población en los valles de Palpa y evidentemente también en aquellos de Nazca. La aparición de grandes centros poblados que antes eran pocos o casi ausentes, así como un nuevo estilo de cerámica distinto en relación con la típica cerámica Paracas y a aquella de Nasca y, en general, el incremento en la producción de petroglifos y geoglifos, nos indica que los valles de Palpa fueron impactados por la presencia de una nueva entidad política y social que propició esos cambios. Nosotros atribuimos esos cambios en los valles de Palpa y de toda la cuenca del río Grande, a la influencia de la tradición Topará, la cual habría favorecido la llegada de nuevos grupos de pobladores que ocuparon más intensivamente los valles y promovieron la formación de nuevas élites que luego darían origen a los nasca como entidad política y social.

\section{La cerámica}

La cerámica del período de transición Paracas-Nasca, también conocida como Proto-Nasca (Strong 1957, Sawyer 1966) o Nasca Inicial (Reindel et al. 1999) ${ }^{12}$, con frecuencia se relaciona con las fases Ocucaje 10 y Nasca 1, debido a la ocurrencia de ciertos rasgos formales y estilísticos que son comparables con los estilos alfareros Paracas Tardío y, en menor grado, Nasca Temprano ${ }^{1} .^{3}$ En esto, tiene mucho que ver el planteamiento que sugiere la existencia de un fuerte lazo de continuidad entre la producción alfarera de ambas sociedades, donde tal vez el cambio más importante fue la introducción de pigmentos minerales aplicados antes de la cocción, típico de la cultura Nasca, en vez de los pigmentos orgánicos aplicados después de la cocción, característico de la cultura Paracas; así como el gradual abandono de la decoración incisa por la decoración pintada (Menzel et al. 1964).

No obstante, la gran cantidad de materiales registrados en los valles de Palpa indican que la cerámica típica de la época de transición presenta rasgos propios y distintivos, tanto en forma como en decoración, así como notables innovaciones tecnológicas ${ }^{14}$. Estos rasgos, vistos en conjunto, muestran un corpus alfarero bastante diferente en relación con la clásica cerámica Paracas y aquella Nasca, con las cuales sin embargo tiene varios rasgos en común. En este sentido, se puede decir que casi todos los tipos alfareros conocidos como componentes de las fases Ocucaje 10 y principalmente Nasca 1, forman parte de este mismo corpus (ver también Carmichael 2016: 122-123).

Durante los trabajos de campo, este corpus alfarero ha sido registrado, casi sin excepción, en la superficie de todos los sitios de este período en los valles de Palpa. Lo mismo se puede decir para el valle de Ingenio (Silverman 2002) y también para los valles de Nasca (ver Strong 1957; Orefici 1996; Schreiber 1998; De La Torre y Van Gijseghem 2005). Asimismo, una excavación de prueba realizada en el sitio de Estaquería ${ }^{15}$, ubicado cerca de la confluencia de los valles de Palpa y río Grande, nos ha permitido obtener información estratigráfica sobre este tipo de cerámica. La excavación fue realizada en la parte central del sitio, donde se encuentran una serie de recintos de planta cuadrangular distribuidos en terrazas bajas y escalonadas, los cuales estaban construidos con muros bajos de doble cara hechos con piedras de campo. Una unidad de 2 por 2 metros localizada en la esquina Norte de uno de los recintos nos permitió registrar dos niveles de ocupación bien definidos. 
El primero correspondiente a un piso asociado a los muros de piedra y el segundo, en un nivel inferior, relacionado con paredes de quincha. En ambos niveles se recuperó una buena cantidad de fragmentos de cerámica, semejante a aquella que con frecuencia se encuentra en la superficie de todos los sitios de este período, pero sin mayores diferencias formales o estilísticas entre los dos niveles.

Teniendo en cuenta estas evidencias, se puede decir que la cerámica típica de este tiempo, se caracteriza por la presencia de vasijas reducidas o negras y aquellas oxidadas que presentan tonos de color marrón, naranja y rojizo. En la mayoría de los casos tienen paredes delgadas técnicamente bien logradas, cuyas superficies presentan buen acabado y cierto grado de pulido. Las vasijas reducidas presentan superficies de tonos grises y oscuros, en donde también hay piezas bien pulidas y con decoración bruñida en el fondo de los cuencos. En este grupo también es frecuente encontrar fragmentos con decoración negativa. Por otro lado, las vasijas oxidadas tienen decoración monocroma hecha en base a la aplicación de engobes de colores rojo, naranja o crema, los cuales en muchos casos presentan motivos pintados en rojo, crema o blanco ${ }^{16}$.

Sin duda la forma de vasija más dominante está representada por varios tipos de platos y especialmente cuencos, los cuales mayormente tienen paredes bajas con diferentes grados de inclinación (Fig. 6). Entre los cuencos, la forma más característica de este período de tiempo, se encuentra un tipo de cuenco de paredes convexas y muy curvadas, los cuales casi no tienen ángulo basal y siguen un contorno convexo y redondeado hacia la base. En algunos casos tienen bases profundas de contorno casi cónico. Este tipo de cuenco es exclusivo de esta época, ya que no existen en la fase Ocucaje 9 ni en la fase Nasca 2. A este tipo le siguen otros cuencos de paredes rectas y bajas con ángulo basal pronunciado, los cuales son semejantes a los del estilo Chongos y constituyen los antecedentes inmediatos de los cuencos característicos de la fase Nasca 2. En el corpus también hay cuencos más altos que tienen paredes convexas y base redondeada, así como unos cuencos o tazones bastante grandes que presentan superficies oscuras al interior y grises o tonos más claros al exterior. Algunos de estos cuencos presentan motivos incisos en el interior y se incluyen en la categoría de ralladores (Menzel et al. 1964: 215-216; ver también Massey 1986: fig. 3.1-3.5; Valdéz 2000: fotos 1, 3-5).

Otras formas predominantes comprenden varios tipos de ollas - con cuello y sin cuello-, botellas y cántaros. Entre estos últimos destaca un tipo bien característico y claramente comparable con los cántaros de las fases Jahuay 3 y Chongos de la tradición Topará (Fig. 7). Por otro lado, solo algunos fragmentos de botellas modeladas de doble pico y de otras vasijas modeladas se han detectado en el registro arqueológico. Estas ocurren en asociación con las formas antes descritas, pero en mínimo porcentaje. Las botellas de doble pico con cuerpos modelados en forma de frutos son típicas de esta época, constituyendo una forma característica del estilo Topará (Peters 1997). Finalmente, también se encuentran fragmentos de antaras que usualmente tienen tonos de color gris oscuro o negro, las cuales por lo general son más pequeñas que sus pares de Nasca y por lo general tienen sus lados curvados (ver Carmichael 2016: figs. 8, 9a-b, 16 y 17).

Desde el punto de vista decorativo, se puede decir que la mayor cantidad de cerámica de este tiempo presenta decoración monocroma lograda en base a la aplicación de engobes de color blanco o crema, seguidos de otros de tonos de color rojo, marrón, naranja y gris. En los platos y cuencos, las formas más frecuentes, se observa además decoración pintada hecha en base a líneas o grupos de líneas dispuestas en forma vertical o diagonal pendientes del borde de las vasijas. Grupos de líneas y círculos también se presentan en base a la técnica del negativo. Asimismo, con frecuencia ocurren algunos motivos geométricos (círculos, escalonados, triángulos, líneas onduladas, etc.) pintados en colores crema o ante sobre fondos de color rojizo y naranja opaco. Estos mismos motivos se presentan en forma incisa, técnica que es utilizada también para delinear motivos naturalistas de plantas, animales y figuras humanas. Esta es la única técnica decorativa que de manera restringida se encuentra en vasijas llanas hasta la fase Nasca $3^{1} .7$ Por otro lado, motivos de círculos y líneas radiales se presentan en forma bruñida en el fondo de los cuencos de color negro. 
$1 / 3$
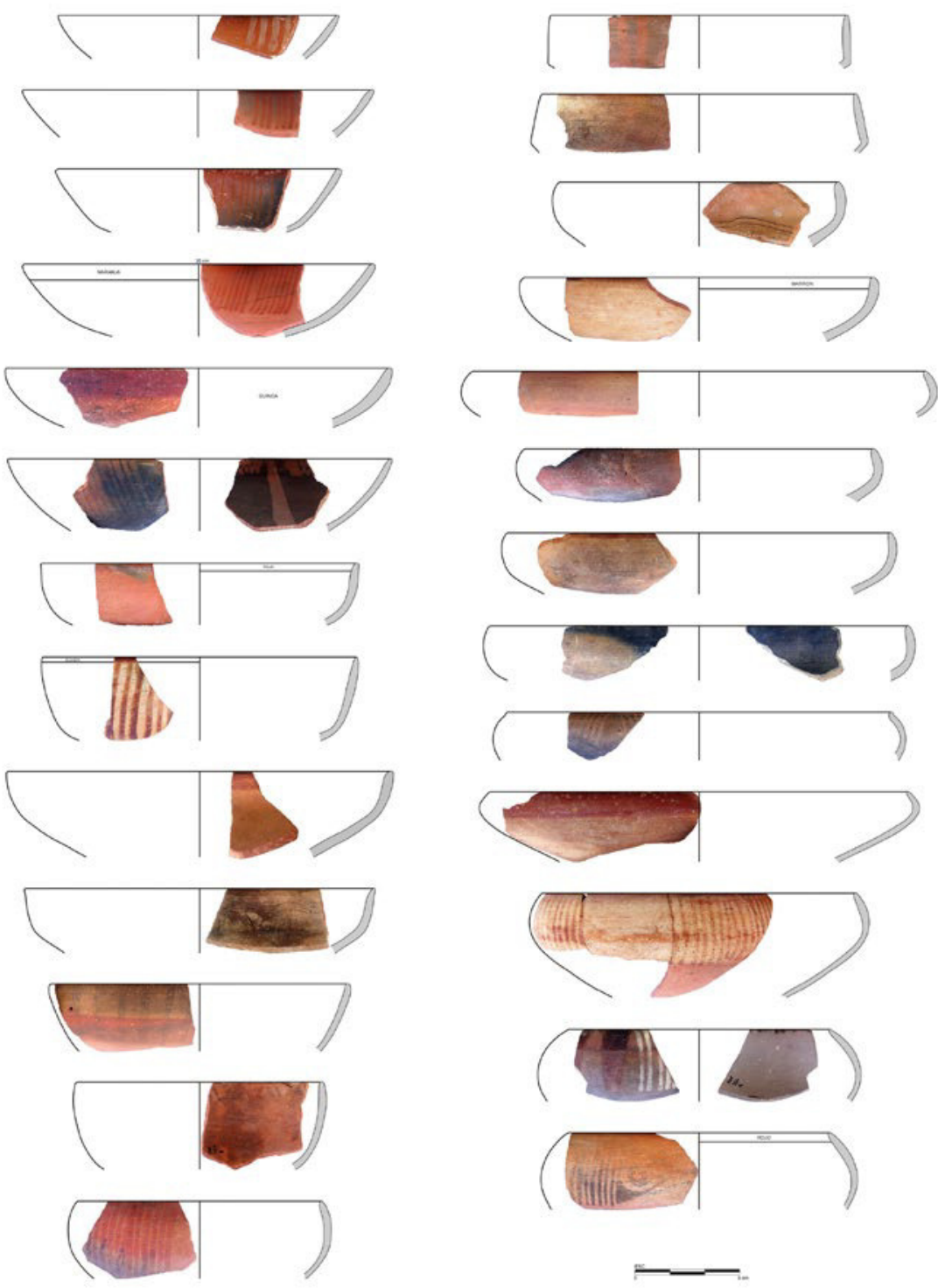

Figura 6. Principales formas de vasijas abiertas y motivos decorativos que caracterizan la cerámica de la época de transición de Paracas a Nasca. Destacan los cuencos bajos de paredes convexas y base casi plana (Gráfico elaborado por los autores). 
$1 / 3$

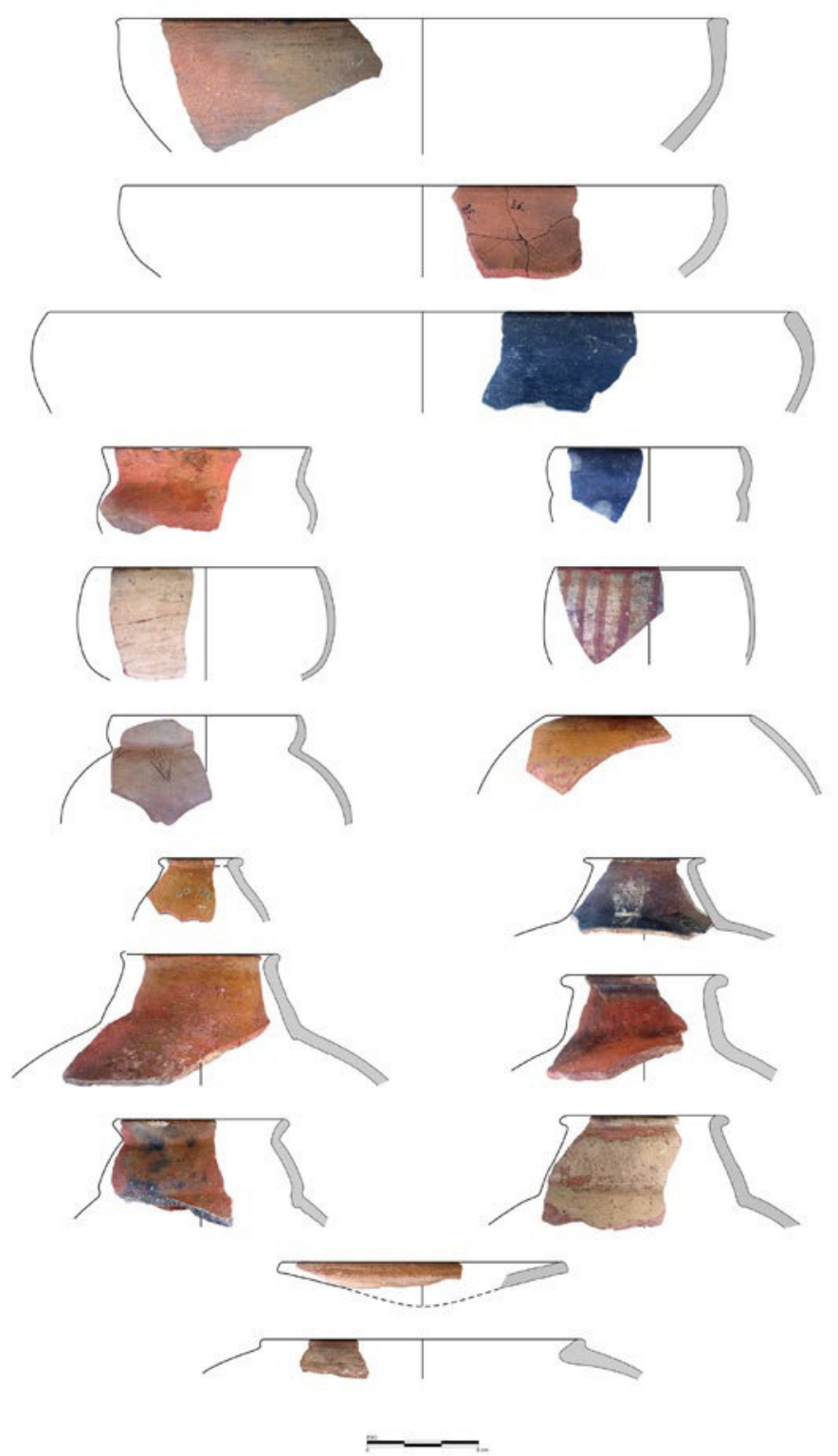

Figura 7. Formas características de las vasijas cerradas de la época de transición de Paracas a Nasca, donde destacan los cántaros relacionados con la fase Jahuay (Gráfico elaborado por los autores). 
En términos generales y en contraste con la sucesiva cerámica Nasca, se puede decir que la cerámica de este tiempo es variada e incluye diversas técnicas decorativas (incisa, bruñida, modelada, negativa, pintada e incisa, etc.), las cuales han sido descritas con detalle por Strong (1957: 21-24) ${ }^{18 \text {, }}$ Menzel, Rowe y Dawson (1964: 254-256) y Massey (1986: 93-109). En este sentido, creemos importante indicar que el tipo conocido como Cahuachi Polícromo Inciso, que en la literatura ha sido usado como uno de los principales rasgos para caracterizar la cerámica Proto Nasca o Nasca 1, apenas está presente en el registro arqueológico y, cuando está presente, ocurre en poca cantidad y casi siempre en asociación con los otros tipos antes indicados. Hacemos referencia a esto, porque este tipo decorativo ha sido considerado como elemento típico de transición entre la decoración incisa, característica de la cerámica Paracas, y la cerámica polícroma y pintada con engobe aplicada antes de la cocción que caracteriza a la cerámica Nasca (Menzel et al.1964: 251; Wallace 1986: 44).

Como ya se dijo antes, una comparación de la cerámica de este tiempo con la típica cerámica Paracas y con aquella típica de Nasca, nos revela que se trata de un corpus de cerámica bastante sencillo, de paredes delgadas, mayormente llana y monócroma pero con un alto grado de calidad técnica. En gran medida, se puede decir que no se parece ni a la una ni a la otra. En este sentido, las marcadas diferencias existentes entre la predominante cerámica incisa de la fase Ocucaje 9 y la cerámica pintada de la fase Nasca 2, considerados en este caso los dos extremos de la época de transición, no dejan dudas de que la producción alfarera de este tiempo introdujo cambios importantes que afectaron los aparentes fuertes lazos de continuidad planteada entre la cerámica Paracas y Nasca (Menzel et al. 1964: 251) ${ }^{19}$.

En este sentido, lo que nos indican los materiales registrados en los valles de Palpa es que, tanto en formas como en decoración, la cerámica de esta época presenta rasgos similares a la cerámica del estilo Topará, aunque al mismo tiempo muestra elementos propios que sugieren la existencia de una cierta independencia cultural. Por esta razón, aquí preferimos denominar a este estilo alfarero simplemente como Proto Nasca, en el cual tuvo mucho que ver la cultura Topará, cuya influencia al final del período Formativo no sólo alcanzó hasta el valle de Ica sino también hasta los valles de la cuenca del río Grande (Wallace 1986: 45). La predominante cerámica monocroma, sin decoración incisa, registrada en los valles de Palpa y Nasca, es muy parecida a la cerámica de las fases Jahuay 3 y Chongos de la cultura Topará, aunque en algunos casos, las paredes de las vasijas no son tan delgadas ni el engobe tan fino como en los valles donde dicha cultura tuvo su centro de desarrollo.

Desde esta perspectiva y en el contexto de la influencia ejercida por la tradición Topará en la región, resulta claro que durante la época de transición de Paracas a Nasca, algunas técnicas decorativas que tuvieron su origen en el estilo Paracas (inciso, negativo, bruñido) se mantuvieron como tipos distintivos, mientras que otros como el Cahuachi Rojo y Blanco y especialmente el Cahuachi Polícromo Inciso, fueron privilegiados como estilos nuevos y de prestigio, claramente vinculados a los grupos de élite de la naciente cultura Nasca. Solo de este modo se puede entender que materiales de ambos estilos (Paracas y Nasca) se encuentren juntos con aquellos del estilo Topará, sugiriendo la coexistencia de los tres estilos (Massey 1991; Peters 1997; Proulx 2006). En este sentido, la situación de estos estilos en los contextos funerarios de los cementerios de la península de Paracas parece haber sido más compleja, lo que amerita una discusión más amplia en el futuro.

\section{Cementerios y contextos funerarios}

Las evidencias registradas en Palpa indican que los cementerios de la época de transición se encuentran casi siempre, en o cerca de los sitios de habitación, en donde ocupan una parte relativamente delimitada del sitio o al interior de las terrazas de habitación, siendo muy raro encontrar cementerios claramente aislados o independientes. En este sentido, se debe indicar que, en varios sitios, especialmente en aquellos multicomponentes, es bastante difícil saber, solo en base a las observaciones de superficie, si los contextos funerarios son intrusivos en un sitio doméstico previamente abandonado o si son contemporáneos con el momento de ocupación. Esta situación se complica aún más 
cuando se presentan ocupaciones posteriores que han afectado los contextos originales. Esto último se observa mayormente en los sitios que se encuentran cerca del borde de los valles, los cuales en muchos casos han sido afectados por ocupaciones posteriores pertenecientes la época Nasca y otras.

En este sentido, debemos señalar que en la mayoría de los casos los cementerios y áreas de enterramiento de esta época, han sido identificados en base a los pozos huaqueados dejados por los buscadores de tesoros, por lo que es importante realizar excavaciones controladas que permitan precisar con mayor detalle los datos que se exponen aquí. Esto se hace especialmente necesario en aquellos sitios en donde hay evidencias de ocupaciones posteriores.

Justamente, durante los trabajos en Palpa hemos tenido la oportunidad de registrar cinco contextos funerarios que habían sido parcialmente saqueados, en los cuales se ha podido documentar algunos rasgos que caracterizan los entierros de esta época. De los cinco entierros estudiados, uno procede de Carapo, otro del sitio PAP-271, ubicado en el valle del río Grande y los otros tres de Belén Alto, sitio localizado en la margen derecha del valle de Ingenio, cerca de la confluencia con el río Grande.

Cuatro contextos funerarios corresponden a individuos adultos que estaban al interior de pozos excavados en el terreno natural. Solo uno pertenece a un infante que había sido colocado al interior de una olla (urna funeraria) de uso doméstico. Los primeros cuatro individuos fueron colocados en posición sentada con las piernas bien flexionadas hacia el pecho y los brazos dispuestos a su alrededor, notándose que la cabeza estaba apoyada sobre las rodillas (Fig. 8). Los cuerpos estaban envueltos con uno o dos tejidos llanos que fueron amarrados con hilos o delgadas fajas tejidas de algodón. En un caso también se había colocado hojas de pacae en su alrededor. En la mayoría de los casos los entierros presentan un buen estado de conservación, notándose incluso en dos de ellos casi toda la piel y los tejidos secos adheridos a los huesos. En uno de estos, además, se observa restos de barro impregnado al cuerpo que se aplicó como parte del ritual mortuorio y que favoreció su conservación. A pesar que los contextos habían sido parcialmente saqueados, en tres casos se ha llegado a recuperar algunas vasijas de cerámica dejadas como ofrenda a los difuntos (Fig. 9).

En todos los casos aquí citados, los cuerpos fueron colocados al interior de pozos sencillos de contorno circular, los cuales fueron excavados en el terreno natural sin mayor revestimiento o tratamiento especial. Los pozos luego fueron rellenados con el mismo material y en algunos casos mezclados con restos vegetales y tierra fina. En ningún caso se han visto piedras o palos que indiquen la presencia de techos o coberturas más elaboradas. Al encontrarse parcialmente disturbadas, tampoco se ha observado señales o indicadores de tumbas. Lo que sí se puede decir en el caso de los contextos procedentes del sitio Belén Alto, es que allí se encuentra un cementerio más o menos delimitado, en donde las tumbas o sepulturas estaban dispuestas en filas, muy cerca de la zona de vivienda y de las terrazas de habitación.

De momento, la muestra estudiada es muy limitada para establecer un patrón funerario, pero no deja de ser interesante destacar la posición sentada en la que fueron colocados los cuerpos, lo cual podría ser un rasgo característico de los entierros de esta época ${ }^{20}$. En todo caso, parece que los entierros en pozo y en urnas parecen haber sido los más recurrentes, los cuales también eran frecuentes en la precedente época Paracas Tardío y la sucesiva Nasca Temprano. En ningún caso hemos observado tumbas más grandes o elaboradas, pero eso puede cambiar en el futuro con la excavación de otros contextos funerarios.

Visto desde una perspectiva más amplia, Lisa DeLeonardis (2012: 201) presenta un sumario interesante sobre el tema, a partir del cual se puede hacer un enfoque sobre los contextos funerarios de la época de transición en relación con aquellos de Paracas y Nasca. En ese sentido, se puede decir que los entierros Paracas tienden a ser mayormente individuales dispuestos en posición extendida —envueltos con tejidos sencillos — - al interior de pozos. Solo en la época Paracas Tardío se nota una mayor variabilidad en el patrón funerario cuando ocurren entierros individuales y múltiples dispuestos en posición sentada, extendida o flexionada al interior de urnas, pozos, cámaras y barbacoas. Estas últimas luego devienen en un rasgo típico de los enterramientos de la época Nasca. 


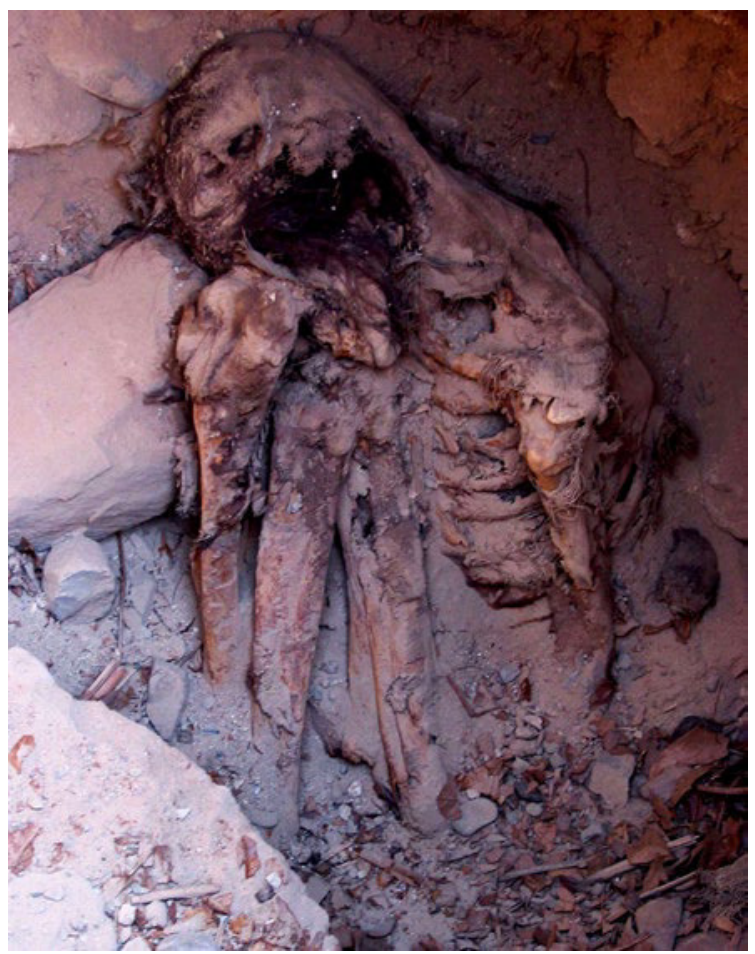

Figura 8. Contexto funerario de la época de transición Paracas-Nasca proveniente de Carapo, donde se puede ver la disposición característica del cuerpo: sentada y con las piernas hiperflexionadas (Foto Johny Isla).
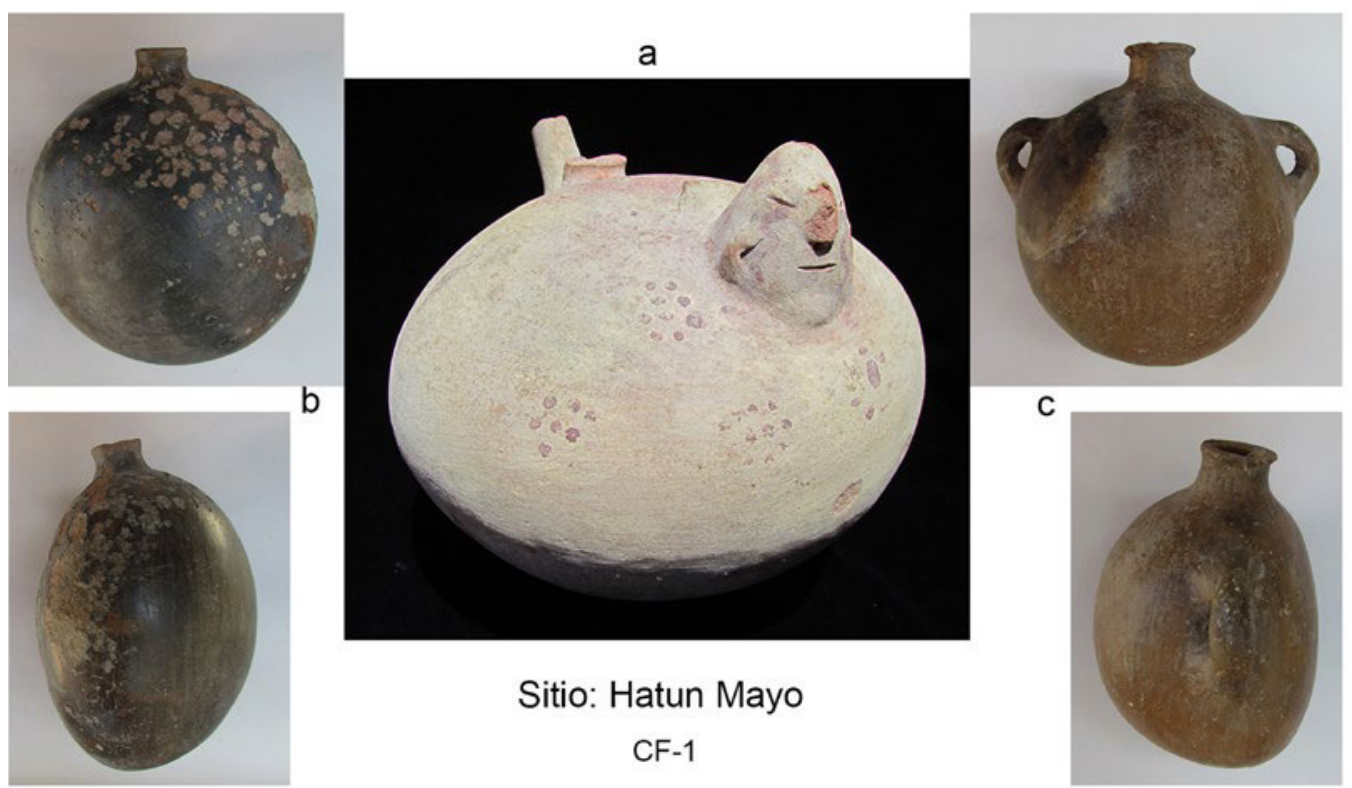

Figura 9. Vasijas que formaban parte del ajuar funerario de uno de los contextos funerarios provenientes de Belén Alto, valle de Ingenio, medidas: a. Diámetro 19.5 centímetros, altura 17 centímetros: b. Diámetro máximo 18.5 centímetros, Diámetro minimo 14 centímetros, altura 20.5 centímetros; c. Diámetro máximo 15.2 centímetros, diámetro mín. 10.4 centimetros, altura 15 centimetros (Foto Johny Isla). 
En el caso de la península de Paracas, durante la época de transición se observa un cambio notable en el patrón de enterramiento con la aparición de fardos funerarios, en donde los individuos fueron dispuestos en posición sentada envueltos con elaborados tejidos bordados y ofrendas de cerámica del estilo Topará. Estos fardos constituyen casos especiales que se relacionan con la fase Necrópolis, en donde además se puede ver la estrecha relación entre las sociedades Paracas, Topará y Nasca (Peters 1997). Fuera de la península, los entierros son individuales y la posición sentada parece haber sido predominante durante la época de transición, la cual se mantuvo durante el desarrollo de los nasca junto con la posición flexionada y especialmente semiextendida de los cuerpos (Isla 2009), los cuales otra vez fueron envueltos con tejidos llanos sencillos como en tiempos Paracas. Las tumbas o contextos Nasca más elaborados evidentemente se distinguen de los rasgos aquí indicados.

\section{Los petroglifos}

Las evidencias indican que la producción de petroglifos en los valles de Palpa empezó durante el Formativo Medio, en la época Paracas Temprano, alrededor del año 800 a.C., y concluyó al final del Formativo Tardío, durante la época de transición entre las culturas Paracas y Nasca (Isla y Reindel 2017 ms.). Aun cuando es bastante difícil ubicar cronológicamente este tipo de arte rupestre, en base a comparaciones estilísticas e iconográficas y hallazgos fechables ( $v$.g. fragmentos de cerámica), ha sido posible reconocer en ellos una larga tradición que empezó por lo menos en las primeras fases de ocupación Paracas en la región, tiempo que coincide con la influencia Chavín en la costa sur. Dicha tradición alcanzó su mayor auge durante la época Paracas Tardío y la época de transición, justo antes del desarrollo de la sociedad Nasca.

Durante los trabajos de campo se han registrado más de 40 sitios con petroglifos, la mayoría de los cuales se localizan en la parte media y media-alta de los valles de los ríos Grande, Palpa y Viscas, en lugares donde se encuentran grandes afloramientos rocosos. Algunos sitios con petroglifos también se encuentran en la parte alta de esos valles, arriba de los 2500 m.s.n.m., en la sierra misma. En la mayoría de casos, los petroglifos fueron grabados en rocas que están en los mismos sitios de habitación o muy cerca de ellos, aunque también hay algunos casos en los que se encuentran en forma aislada en laderas y quebradas. Solo en unos pocos casos se han registrado petroglifos cerca de espacios abiertos pero delimitados, en la cima de colinas o en relación con plataformas o terrazas naturales, los cuales parecen haber funcionado como lugares de reunión en donde se realizaban actividades religiosas o ceremoniales.

Justamente uno de estos sitios es Chichictara, un lugar emblemático de la provincia de Palpa, en donde se encuentra la más grande concentración de petroglifos de toda la región. Este sitio se localiza en la parte media alta del valle de Palpa, en una zona donde el valle es relativamente angosto y en la que se encuentran varios afloramientos rocosos que se localizan en la parte alta de los cerros que bordean la margen izquierda del valle. Cada uno de estos afloramientos han sido registrados como sectores independientes, en los cuales se han identificado más de 158 piedras con más de 400 figuras grabadas pertenecientes a todas las épocas de desarrollo Paracas (800-200 a.C.) y a la época de transición de Paracas a Nasca (Matos 1987).

De particular importancia son los sectores 2 y 3, los que, además de concentrar la mayoría de petroglifos existentes en el sitio, en su parte más alta presentan espacios planos y delimitados que parecen haber funcionado como lugares de reunión. En el sector 3, además, se encuentra un grupo de terrazas de habitación y un pequeño cementerio. En la superficie de ambos sectores se ha encontrado fragmentos de cerámica Paracas Tardío y de la época de transición de Paracas a Nasca, lo que indica con bastante certeza que fue durante ese tiempo en el que se produjeron la mayor cantidad de petroglifos. 
En este sentido, si bien los primeros petroglifos se hicieron en la época Paracas Temprano y luego en la época Paracas Medio, en base a comparaciones iconográficas y la cerámica asociada se puede decir que la mayoría de petroglifos en Chichictara pertenecen a la época Paracas Tardío y, principalmente, a la época de transición de Paracas a Nasca. Un detallado estudio de los petroglifos de Chichictara, especialmente del sector 2, ha sido realizado por Peter Fux (2012) en el marco de las investigaciones del Proyecto Nasca-Palpa.

Desde una perspectiva más amplia, se puede decir que los petroglifos registrados en los valles de Palpa pertenecen a diferentes épocas del desarrollo Paracas, notándose un incremento notable durante el período de transición de Paracas a Nasca, tiempo en el cual fueron más frecuentes las representaciones de figuras antropomorfas (Fig. 10). Justamente, en esta clase de figuras es donde se observa con mayor detalle el traslado de imágenes de las piedras a la superficie del terreno (Fig. 11), con lo cual los geoglifos poco a poco fueron reemplazando a los petroglifos, para constituirse una de las principales manifestaciones culturales de la región, la cual, como todos sabemos, alcanzó su mayor esplendor durante el desarrollo de los Nasca (Reindel et al. 1999).

\section{Los geoglifos}

En las pampas y laderas desérticas que se encuentran entre los valles de Palpa e Ingenio, se ubica la segunda concentración más grande de geoglifos de la región, la mayoría de los cuales se dibujaron durante el desarrollo Nasca, entre los años 50 a 650 d.C. Estos geoglifos son iguales en forma, técnica constructiva y función a aquellos geoglifos dibujados en las pampas de Nasca, en los cuales se nota un claro predominio de los trazos rectos y geométricos -líneas, trapecios y campos barridos-, con respecto a los motivos figurativos. Un completo estudio de una parte de los geoglifos de Palpa ha sido realizado por Karsten Lambers en el marco del Proyecto Nasca-Palpa (Lambers 2005; ver también Reindel et al. 2003, 2006).

Estudios complementarios realizados en Palpa, en la misma zona en donde se encuentran los geoglifos Nasca, nos ha permitido identificar y documentar más de 50 nuevos geoglifos que fueron representados, ya sea en forma individual, o en grupos, sobre las laderas de las colinas y de las planicies que bordean los valles de Palpa ${ }^{21}$. Se nota una concentración especial en la zona comprendida entre los sectores de San Ignacio y Piedras Gordas, al sur de la ciudad de Palpa. La mayoría de estos geoglifos representan motivos figurativos, entre los que destacan figuras zoomorfas (aves y felinos), figuras antropomorfas y seres míticos, aunque también se han identificado algunos geoglifos geométricos que comprenden simples líneas, trapecios y algunos pequeños campos o espacios barridos. Entre todas, de particular importancia son las figuras antropomorfas, las cuales son las más numerosas y las que se representan solas o en grupos, en la mayoría de los casos con el cuerpo de frente y los brazos abiertos, mientras que sobre la cabeza llevan una especie de tocado representado por líneas que simbolizan penachos de plumas (Fig. 11). Esta figura se repite tanto en los petroglifos como en la cerámica de la época de transición de Paracas a Nasca.

Desde el punto de vista constructivo, estos geoglifos fueron hechos mediante la combinación de dos técnicas: la extracción y acumulación de las piedras, con lo cual se llegaron a trazar figuras en alto y bajo relieve que resaltan por el contraste más oscuro del terreno. En este sentido, en muchos casos el cuerpo y las cabezas de las figuras se representaron con áreas y líneas barridas, mientras que los ojos y las bocas se formaron con acumulaciones de piedras. Sólo en algunos pocos casos se hicieron figuras enteras en bajo relieve, es decir con sus contornos formados por la superficie intacta del terreno o, al revés, figuras en alto relieve, formadas por la acumulación de piedras sobre un fondo barrido y de color más claro.

Hasta aquí resulta evidente que estos geoglifos son técnica y estilísticamente diferentes a los famosos geoglifos de la época Nasca. Así, mientras que los geoglifos Nasca son más grandes y se trazaron sobre superficies mayormente planas, estos geoglifos son más pequeños y se dibujaron 

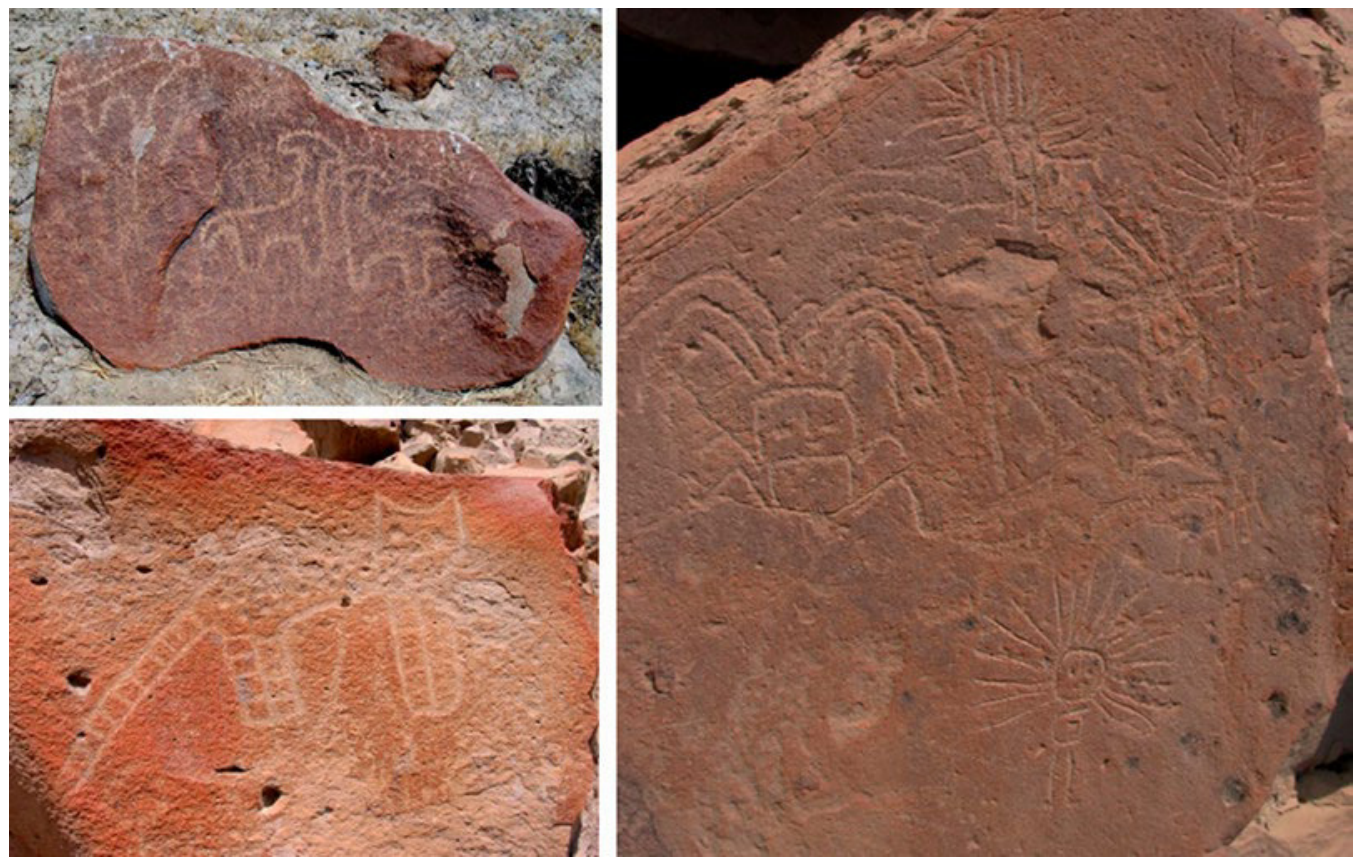

Figura 10. Ejemplos de algunos petroglifos pertenecientes a la época de transición en los valles de en Palpa. La mayor concentración de petroglifos registrados en los valles de Palpa se encuentran en el sitio de Chichictara, Palpa (Fotos Johny Isla y Markus Reindel).

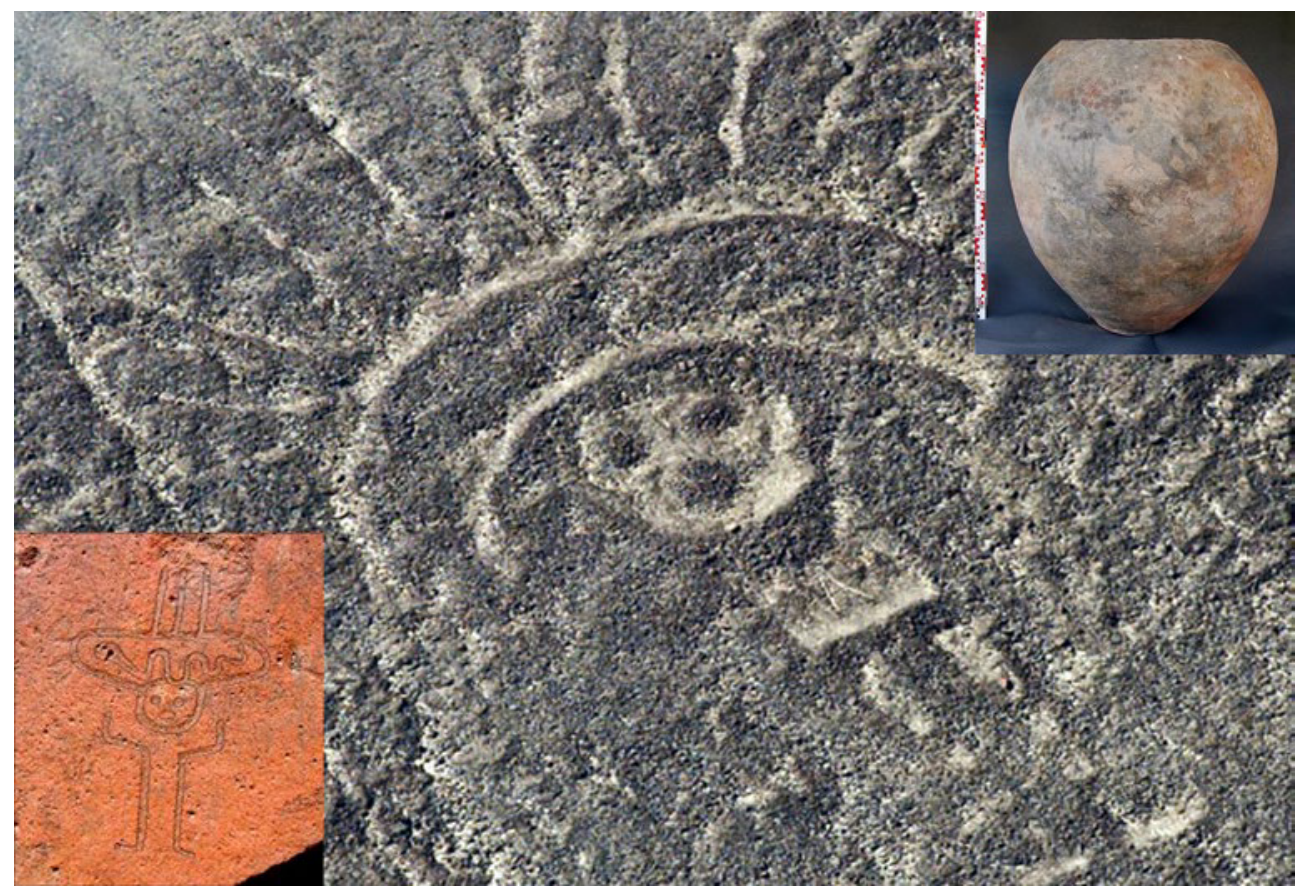

Figura 11. Gráfico que muestra la representación de personajes antropomorfos típicos de la época, los cuales primero fueron representados en las piedras (petroglifos), luego en las laderas (geoglifos) y finalmente en la cerámica (Foto Johny Isla). 
sobre laderas y superficies inclinadas. Otra diferencia resaltante es que mientras los geoglifos Nasca se hicieron solo retirando las piedras de la superficie (barrido), estos geoglifos combinan técnicas de barrido y acumulación de piedras.

Ante la ausencia de materiales diagnósticos que nos ayuden a fijar con mayor certeza el tiempo en que se dibujaron estos geoglifos, su filiación cultural se determinó en base a comparaciones de sus rasgos formales y estilísticos con aquellos motivos presentes en la cerámica y los textiles de las épocas Paracas y Nasca. Según esto, se puede decir que los primeros geoglifos en Palpa se empezaron a dibujar en la época Paracas Tardío, aumentando su frecuencia durante la época de transición de Paracas a Nasca (Isla y Reindel 2007). Es así que algunos de ellos muestran claramente paralelos iconográficos con motivos de la época Paracas Tardío, como el caso de las aves y felinos o del llamado Ser Oculado, la divinidad principal de la época Paracas Tardío (Massey 1991: 239); mientras que otros muestran un gran parecido con los motivos representados en los textiles de la fase Necrópolis (Fig. 12), los cuales se relacionan con la tradición Topará. También en este caso, el notable incremento en la producción de geoglifos durante la época de transición de Paracas a Nasca parece haber sido impulsado por la influencia Topará en la zona.

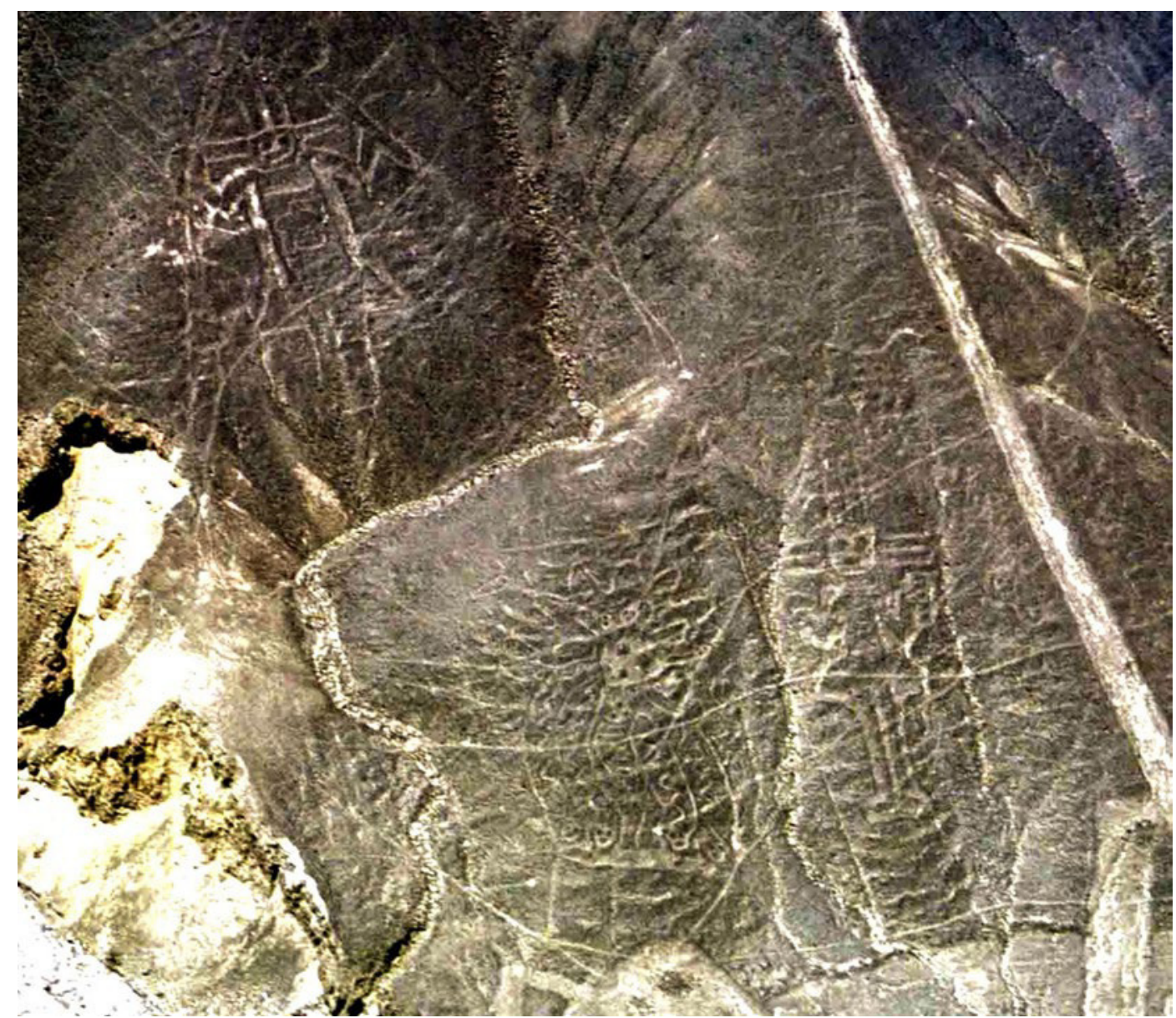

Figura 12. Grupo de geoglifos que se conocen con el nombre de Templo a la Fertilidad, ubicados en una ladera de los cerros al sur de Llipata, Palpa. Muestra figuras comparables con imágenes representadas en los textiles de la fase Necrópolis (Foto Johny Isla). 
Finalmente, resulta claro que en ningún caso, estos geoglifos se parecen o son comparables con los geoglifos Nasca. Además, en varios sitios se ha llegado a documentar la superposición estratigráfica entre estos geoglifos y aquellos de filiación Nasca, en donde se observa que los geoglifos más antiguos han sido parcialmente borrados o cortados por los geoglifos más grandes y geométricos de la época Nasca. Desde este modo, se puede decir con confianza que estos geoglifos constituyeron los antecedentes inmediatos de los famosos geoglifos Nasca.

\section{Cronología}

La ubicación cronológica de la época de transición de Paracas a Nasca, ha sido establecida en base a cinco fechados de radiocarbono provenientes de excavaciones realizadas en el sitio de Estaquería, en el valle de Palpa. Las muestras fueron obtenidas de contextos bien definidos que fueron registrados al interior de un recinto delimitado con muros de piedras. Dos muestras — parte de un poste y una muestra orgánica-, provienen de un piso en el cual había restos de un fogón y varios hoyos de postes. Las otras tres muestras provienen de otro nivel de uso ubicado inmediatamente debajo del piso antes indicado, el cual se encontraba asociado a paredes de quincha y otros tres postes de madera. En relación con ambos niveles de uso se ha recuperado fragmentos de cerámica Proto Nasca o Nasca Inicial, los cuales se relacionan con el estilo Topará. Las cinco fechas calibradas se encuentran en un rango entre 95 a.C. y 130 d.C. (Fig. 13).

Las dataciones fueron adicionalmente analizadas y calibradas con el programa Oxcal en combinación con la información estratigráfica, así como también con las fechas resultantes de la precedente época Paracas Tardío y de la sucesiva época Nasca Temprano. Como resultado de estos análisis el período de transición Paracas-Nasca se puede ubicar entre los años 120 a.C. y 90 d.C. (Fig. 14).

Atmospheric data from Stuiver et al. (1998); OxCal v3.8 Bronk Remsey (2002); cub r.4 sd 12 prob uspichron]

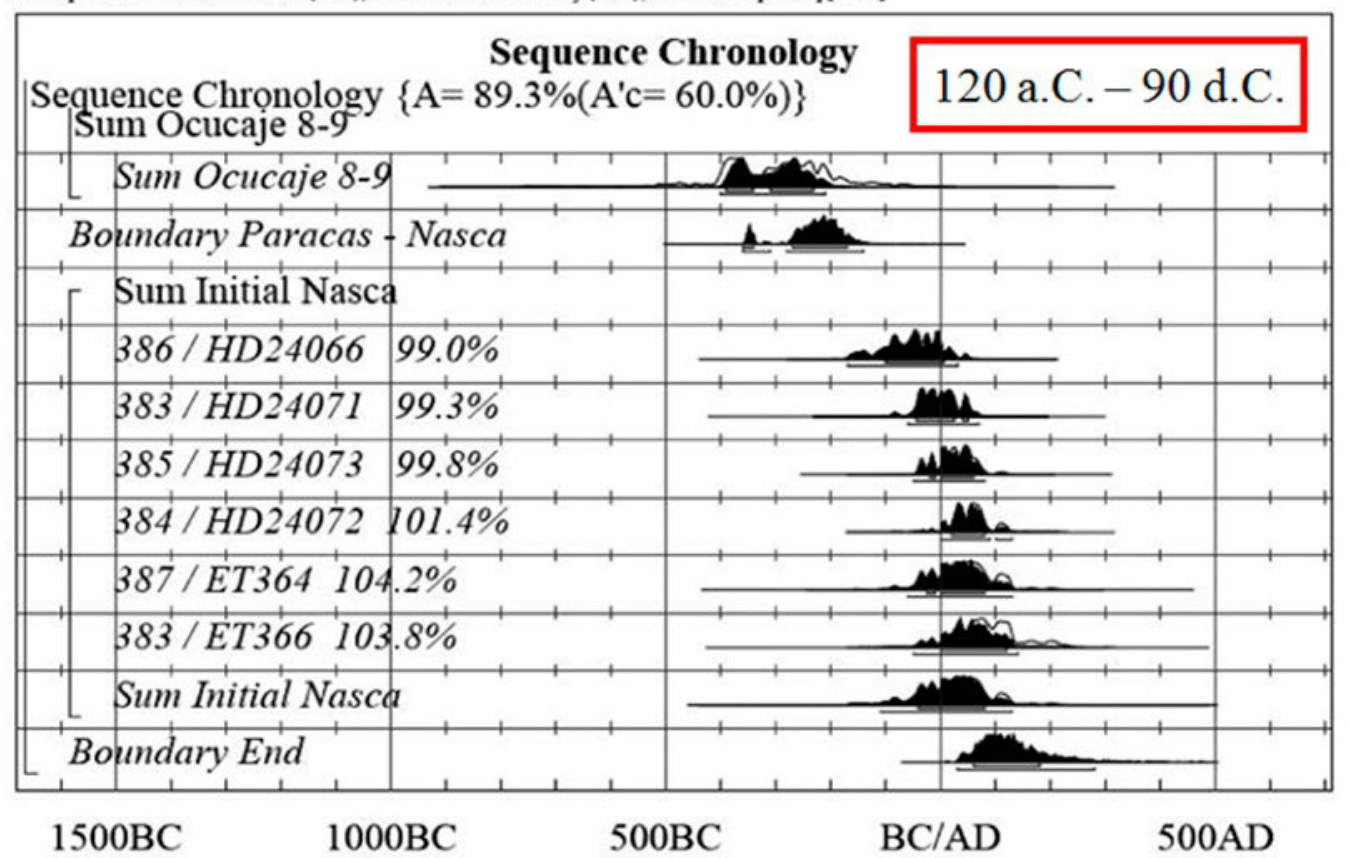

Figura 13. Fechados de radiocarbono obtenidos en base a muestras procedentes de contextos bien definidos del sitio de Estaquería, Palpa. Fechas calibradas con 1 o según Unkel 2006 (cuadro elaborado por Ingmar Unkel). 


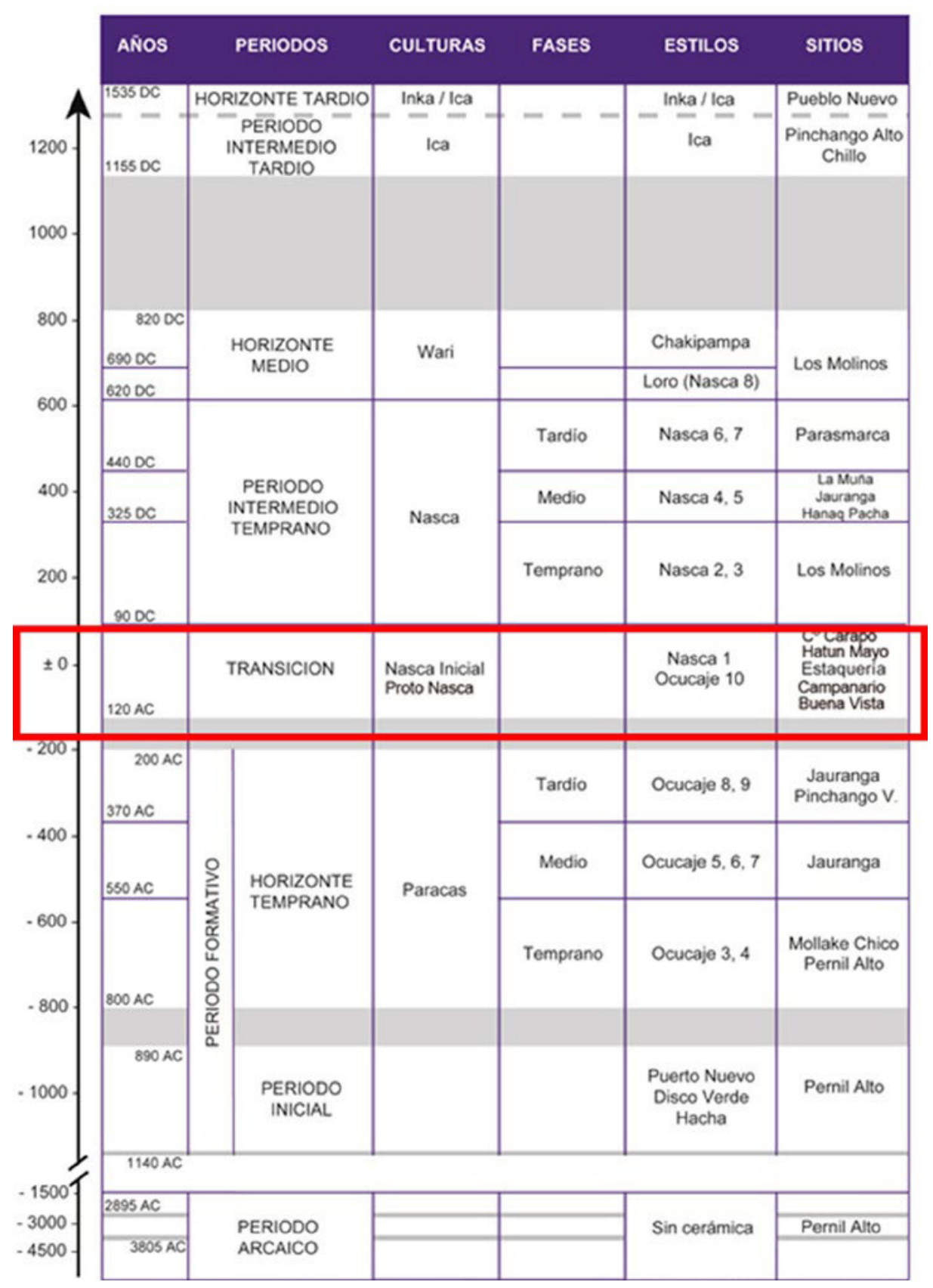

Figura 14. Tabla cronológica de los valles de Palpa elaborada en base a más de 150 fechados de radiocarbono (según Unkel 2006 y 2007). El recuadro marca la época de transición entre Paracas y Nasca (Tabla elaborada por Ingmar Unkel). 
En este cuadro se puede ver la ubicación actual del período de transición Paracas-Nasca, en el contexto general de la cronología de los valles de Palpa. No obstante, es importante indicar que las pocas muestras analizadas todavía dejan un lapso de tiempo inseguro que esperamos solucionar con futuras investigaciones.

\section{Discusión y comentarios finales}

Tradicionalmente, la transición de Paracas a Nasca en la costa sur ha sido enfocada en base a criterios estilísticos observados en la producción alfarera de ambas sociedades. De este modo, se plantea que el punto de quiebre entre ambas estuvo marcado por el uso de pinturas de engobe aplicadas antes de la cocción, típica de Nasca, en vez de la pintura de resina aplicada después de la cocción, típica de Paracas (Menzel et al. 1964: 251). Visto en perspectiva, básicamente se trataba de una innovación tecnológica que no implicaba cambios importantes en la organización política de las poblaciones de ese tiempo, ni tenía que ver con la predominancia de otros grupos o poblaciones. De este modo, se entendía que Paracas y Nasca formaban parte de una misma tradición estilística, en cuya transición ocurrieron cambios menores y graduales 22 .

A diferencia de esta concepción general, las evidencias documentadas en los valles de Palpa indican que la transición de Paracas a Nasca, no fue tan gradual como normalmente se piensa sino más bien bastante abrupta, la cual estuvo marcada por cambios importantes en el patrón de asentamiento, en la producción alfarera, en el incremento en el trazado de petroglifos y geoglifos, etc. Además, las evidencias que se conocen de los valles de Nasca indican que esta situación se repitió por igual en todos los valles de la cuenca del río Grande (ver Browne 1992, Orefici 1996; Silverman 2002; Vaughn y Van Gijseghem 2007). Todos estos factores necesariamente debieron implicar cambios importantes en la estructura y organización de la sociedad, la cual, teniendo en cuenta las condiciones medioambientales de la región (Eitel y Mächtle 2009; Mäxhtle y Eitel 2013), debió tener los mayores cuidados para alcanzar un óptimo manejo del espacio y de sus recursos. Por consiguiente, todos estos cambios contradicen de algún modo la idea de una transición gradual de una sociedad a otra.

En este sentido, tal vez el cambio más importante ocurrió en el patrón de asentamiento, el cual durante este tiempo registró un repentino y notable incremento en el número y tamaño de los asentamientos con relación a la precedente ocupación Paracas y a la sucesiva Nasca. Las evidencias indican claramente que en esta época se duplicó el número de asentamientos con respecto a la época precedente (Paracas Tardío), la mayoría de los cuales luego fueron abandonados antes de la época Nasca Temprano.

Estos cambios los atribuimos al impacto que tuvo la influencia Topará en los valles de Palpa al final del Período Formativo, en relación con las últimas fases - Ocucaje 9 y 10 - de desarrollo de la cultura Paracas, la cual, según todas las evidencias conocidas, tuvo el mismo impacto en todos los valles de la cuenca del río Grande (Wallace 1986), llegando incluso hasta Acarí, en donde erróneamente es considerado como parte de una tradición local denominada Huarato (Valdéz 1998: 98, 2000, 2006). En este contexto, los poblados de este tiempo en los valles de Palpa presentan casi las mismas características de aquellos de Ica y en menor escala de Pisco (Massey 1986; Peters 1997), aunque según el tamaño de los mismos, en ellos se puede notar una jerarquía de hasta dos niveles de asentamiento. El nivel más alto en la zona estudiada estaba representado por sitios como Campanario, Carapo, Buena Vista o Belén Alto, en todos los cuales, además de las numerosas terrazas de habitación, se observan recintos y espacios de aparente uso público y ceremonial pero no edificios con arquitectura pública o monumental.

Este evento parece haber ocurrido cuando los valles de Ica, Pisco y Chincha, considerados como el centro principal de desarrollo de la cultura Paracas, experimentaron drásticos cambios en el patrón de asentamiento debido al crecimiento y aglutinamiento de la población, aunque en todos ellos todavía falta investigar los sitios con arquitectura pública o monumental de esta época (Peters 2013; 
Tantaleán et al. 2013). En este punto, es importante destacar que, para el valle de Chincha, durante la época Paracas, se observa la existencia de un ordenamiento territorial basado en un patrón urbano en el que destacan varios edificios con arquitectura monumental (Canziani 1992, 2009, 2013).

Desde esta perspectiva, es importante indicar que, para este mismo tiempo en Nasca y Palpa, el nivel más alto en la jerarquía de asentamientos estaba representado por Cahuachi, sitio ubicado en el valle de Nazca, en donde además de áreas de vivienda y habitación, habían edificios públicos con arquitectura monumental como el denominado Templo del Escalonado (Orefici 1988). Entre otras construcciones con adobes cónicos, este edificio constituye una de las primeras estructuras arquitectónicas de carácter monumental descubiertas en Cahuachi, el cual luego fue cuidadosamente rellenado y cubierto durante la época Nasca Temprano, con materiales pertenecientes a las fases Nasca 2 y Nasca 3. Las evidencias indican que desde entonces Cahuachi había asumido el rol de sitio más importante en toda la cuenca del río Grande, desde donde ejercía un rol predominante en toda la costa sur (Silverman y Proulx 2002; Vaughn y Van Gijseghem 2007; Tinteroff 2008) ${ }^{23}$.

Otro sitio que también parece haber tenido un rol importante en este tiempo es La Ventilla, sitio bastante grande ubicado en el valle de Ingenio, el cual, en oposición a Cahuachi, ha sido considerado como el centro urbano de la época Nasca Temprano (Silverman 1986). Sin embargo, según las evidencias observadas en la superficie, parece más probable que la mayor cantidad de muros y patios grandes presentes en el sitio hayan sido establecidos en la época transicional, dejando solo los montículos de adobe para la época Nasca Temprano, lo que desde ya disminuye el supuesto alto estatus que tenía La Ventilla durante esa época. En tal sentido, los grandes patios delimitados con muros bajos en la Ventilla parecen repetir de algún modo el modelo arquitectónico que se observa en el sitio de Chongos, en el valle de Pisco (Peters 2013). Las excavaciones que vienen realizando arqueólogos de la Universidad de Yamagata, liderados por Masato Sakai, seguramente ayudarán a aclarar esta situación.

El notable incremento ocurrido en el número y tamaño de los asentamientos durante la época de transición de Paracas a Nasca, evidentemente son el resultado en un aumento demográfico que solo es comparable con lo ocurrido siglos después durante el Período Intermedio Tardío, cuando las condiciones de humedad volvieron a ser como antes — durante todo el Formativo- y prácticamente se produjo un repoblamiento de los valles de Palpa ${ }^{24}$ En este contexto, también se incrementó la producción de petroglifos y geoglifos, los cuales anteceden a los famosos geoglifos de la época Nasca.

Algunos investigadores han planteado que el aumento en el número de habitantes se debería a la migración de poblaciones Paracas hacia los valles de la cuenca del río Grande (Silverman 1994: 378; Schreiber y Lancho 2003: 14; Van Gijseghem 2004, 2006; Vaughn y Van Gijseghem 2007: 815). La razón para este planteamiento se debe a que, solo hasta hace algunos años atrás, se tenía la idea de que los valles de la cuenca del río Grande no formaban parte del área nuclear de la cultura Paracas, sino más bien su periferia (Silverman 1994, 1996: 131). Las pocas evidencias de ocupación Paracas conocidas hasta entonces en los valles de Palpa y Nasca, en efecto, dejaban abierta esa posibilidad. Por otro lado, tampoco se tenía un buen conocimiento sobre los materiales Topará, los cuales, en el caso de la cerámica, usualmente fueron clasificados ya sea como Paracas (Ocucaje 10) o como Nasca (Proto Nasca o Nasca 1), siguiendo criterios estilísticos. De este modo, hasta hace poco, tampoco se tuvo una clara idea sobre los alcances que tuvo la expansión de los Topará hacia los valles del Sur.

A la luz de las evidencias documentadas en los últimos años en los valles de Palpa, ahora sabemos que la ocupación Paracas en esos valles fue lo suficientemente estable y permanente a lo largo del tiempo, especialmente durante las épocas Paracas Medio y Paracas Tardío (Reindel e Isla 2006; Isla y Reindel 2007). Entonces, el cambio en el patrón de asentamiento y el incremento poblacional ocurrido durante la época de transición de Paracas a Nasca, no se debería a la migración de poblaciones Paracas sino de poblaciones Topará, situación que concuerda bastante bien con las evidencias registradas en el valle de Ica (Massey 1986, 1991) ${ }^{25}$. En ese sentido, también la parte alta 
de los valles de Palpa, que ya mostraba un cierto grado de integración con la costa durante la época Paracas Tardío (Reindel e Isla 2013), en la época de transición muestra un mayor grado de integración costa-sierra debido a la influencia Topará en esa zona (ver Reindel e Isla en este volumen). Esta zona, que geográficamente se encuentra más cerca de la cabecera de los valles de Ica y Pisco, presentaba las condiciones ideales para la crianza de camélidos y por ende para la obtención de fibras de camélidos, tan requeridos en la costa durante la fase Necrópolis (relacionada con Topará).

En este contexto, se entiende que Topará se extendió de la zona de Chincha-Pisco a la de Ica-Palpa-Nasca, afectando el normal desarrollo de los paracas en esos valles al final de la fase Ocucaje 9. Este evento marcó el inicio de la época de transición, tiempo en el cual se generaron los cambios culturales y las innovaciones tecnológicas que después dieron origen a los Nasca. Desde esta perspectiva, este planteamiento supone que, primero hubo un tiempo en el que se dio el desarrollo e interacción entre Paracas y Topará, y luego otro entre Topará y Nasca. Este escenario ha sido ampliamente analizado por Ann Peters (1997), quién sostiene que en este tiempo en la costa sur hubieron tres tradiciones culturales (Paracas, Topará y Nasca), que interactuaron temporal y espacialmente, incluyendo cierto grado de superposición entre sí (op. cit.: 463). Similar posición es planteada por Vanessa Tinteroff (2008: 405), quien utiliza el término de «mutación cultural» para calificar esta etapa de transición ${ }^{26}$, aunque ella solo considera el factor endógeno del evento, es decir, el de una transformación progresiva de un tronco común Paracas en tres entidades políticas que luego interactúan entre sí: Paracas, Topará y Nasca. Como hemos visto acá, la interacción entre Paracas y Nasca habría ocurrido a través de Topará y no directamente entre sí.

En conclusión, podemos decir que el período de transición de Paracas a Nasca puede ser caracterizado como una etapa de experimentación y cambio en toda la costa sur, como ocurrió casi en todos los Andes al final de período Formativo, en donde resulta evidente que los Topará jugaron un rol decisivo en el incremento de la complejidad social y la interacción regional. En este sentido, fueron los Topará los que se encargaron de conservar y transformar algunos rasgos culturales Paracas que luego se manifestaron en el desarrollo de los $\mathrm{Nasca}^{27}$, los cuales permiten ver lazos lógicos de continuidad cultural entre ambas formaciones sociales.

\section{Agradecimientos}

Los resultados presentados en este artículo se derivan de las investigaciones interdisciplinarias realizadas en el marco del Proyecto Arqueológico Nasca-Palpa, los cuales fueron auspiciados por la Fundación Suiza Liechtenstein para Investigaciones en el Exterior (FSLA), el Ministerio Federal de Educación e Investigación de la República Federal Alemana (BMBF) y la Comisión de Arqueología para Culturas Extraeuropeas (KAAK) del Instituto Arqueológico Alemán (DAI). Los trabajos de campo y las investigaciones de los proyectos Nasca-Palpa y Palpa-Lucanas han sido debidamente autorizadas por el Instituto Nacional de Cultura (INC), hoy Ministerio de Cultura. Dicho esto, queremos expresar nuestro especial agradecimiento a todos los colegas, técnico y especialistas del Perú y Alemania, quiénes participaron y colaboraron en las excavaciones y en el análisis de los materiales incluidos en este artículo.

\section{Notas}

1 También en 2008, en la 73a reunión anual de la Society for American Archaeology, realizada en Vancouver, Canadá, numerosos colegas expusieron sus investigaciones sobre el tema en el Simposio Interaction, Innovation and Social Change: The Paracas-Nasca Transition, organizado por Ann H. Peter y Hendrik VanGijseghem.

2 Aquí debemos remarcar que todavía falta saber con mayor detalle lo que se denomina como cultura Topará y cuáles fueron sus rasgos característicos más allá de sus fases o tipos alfareros. Su definición todavía no es clara ni en su aparente centro de origen (los valles de Cañete, Chincha 
y Pisco) y por ende menos en los otros valles donde ejerció influencia. Ese es un tema pendiente de un estudio más detallado y sistemático.

${ }^{3}$ La cuenca del río Grande se localiza mayormente entre las regiones de Ica por la costa y Ayacucho por la sierra, y sólo su extremo norte se encuentra en la región de Huancavelica, siempre por la sierra. Se trata de un extenso territorio sumamente árido que comprende al tablazo de Ica y las pampas desérticas de Palpa y Nazca, así como la yunga costeña y los valles altos de la vertiente occidental de los Andes, entre la costa del océano Pacífico y la cordillera de los Andes. Se debe indicar que hasta el momento solo hemos realizado trabajos de reconocimiento superficial en el valle de Santa Cruz.

${ }^{4}$ Las investigaciones en la zona de sierra se realizan en la parte alta de los valles de Palpa y Viscas, que en la zona corresponde a la jurisdicción de los distritos de Llauta, Laramate y Ocaña, Provincia de Lucanas, región de Ayacucho.

5 Las investigaciones en la sierra se realizan en el marco del Proyecto Arqueológico Palpa-Lucanas, siempre bajo la dirección de los autores del presente artículo.

${ }^{6}$ El número de sitios arqueológicos se ha incrementado en los últimos años con la ampliación de los trabajos de prospección hacia la parte alta de los valles de Palpa, específicamente en los valles de Palpa y Viscas, a lo largo de la yunga desértica y en la sierra misma, entre los 2500 y 4500 m.s.n.m.

7 Toda la parte baja del sitio, por su lado sur, fue reocupada durante la época Nasca Temprano y Nasca Medio. Además, el cementerio actual de Palpa y otras viviendas actuales se han establecido sobre las ocupaciones antes indicadas, destruyendo los restos arqueológicos.

${ }^{8}$ Lamentablemente esta parte del sitio ha sido severamente afectado por el avance urbano del centro poblado San Pedro de Carapo, lo cual ha provocado la destrucción de muchas estructuras arquitectónicas.

9 El sitio de Belén Alto (PAP-1140) corresponde al sitio 220 en los registros de Helaine Silverman. Tiene más de 10 hectáreas ocupadas por construcciones distribuidas por sectores o grupos que se encuentran mayormente en la parte media y alta de las laderas. La parte baja del sitio ha sido densamente cubierta por construcciones pertenecientes al Período Intermedio Tardío. En la actualidad gran parte de la sección más baja del sitio ha sido nivelada con maquinaria pesada y convertida en campos de cultivo.

${ }^{10}$ Una situación similar ocurrió sólo durante el Período Intermedio Tardío, cuando se alcanzó otro de los picos más altos en el número y tamaño de los asentamientos. Esta situación se encuentra en relación con un nuevo incremento en las condiciones de humedad en la región, las cuales volvieron a ser como eran en el Período Formativo (Eitel et al. 2005).

${ }^{11}$ El nivel más alto de la producción agrícola en los valles de Palpa y Nazca debe haber ocurrido en las épocas Nasca Temprano y Nasca Medio con la implementación de sistemas de riego asociados a los puquios o galerías filtrantes (Schreiber y Lancho 2003, 2006).

${ }^{12}$ Katharina Schreiber (1998) propuso el nombre de Montana para identificar la cerámica de la época de transición de Paracas a Nasca en los valles de Nazca, la cual sigue la definición clásica que se relaciona con las fases Ocucaje 10 y Nasca 1.

${ }^{13}$ La definición de estas fases ha sido hecha en base a los materiales procedentes de la zona de Ocucaje, en el valle de Ica y de Cahuachi, en el valle de Nazca (Strong 1957; Menzel et al. 1964).

${ }^{14}$ Según Proulx (2006: 30-31) la transición del estilo Paracas al estilo Nasca fue abrupto, con una gran cantidad de innovación en el uso de engobes y formas de vasijas.

${ }^{15}$ Según referencias de los pobladores locales, la sección del valle donde se localiza el sitio excavado se llama Estaquería, nombre que fue asignado años atrás debido a la existencia de una gran cantidad de postes de huarango en la zona. Por lo tanto, este sitio no tiene nada que ver con el famoso sitio de Estaquería localizado en el valle de Nazca. 
${ }^{16}$ Una descripción más completa de la cerámica de este tiempo ha sido realizada por Sarah Massey (1986: 93-109), donde además se debe incluir parte de los materiales de sus fases Early Horizon 3 (que corresponde a la fase Ocucaje 9) y Early Intermediate Period 2 (que corresponde a la fase Nasca 2).

${ }^{17}$ Solo raramente se han registrado vasijas de tipo doméstico decoradas con motivos incisos hasta la fase Nasca 3 (Proulx 1970: Plate 24 B y Plate 27 E, F).

${ }^{18}$ Aquí también se debe incluir la descripción de los tipos descritos en Cahuachi como Paracas Tardío por Strong (1957: 16-21).

${ }^{19} \mathrm{La}$ continuidad de elementos y técnicas decorativas entre Ocucaje 10 y Nasca 1 son evidentes y claramente apoyan el planteamiento de Menzel, Rowe y Dawson (1964), pero no así si ambas fases se consideran juntas como parte de un mismo corpus alfarero en contraste con las fases Ocucaje 9 y Nasca 2, las cuales marcan el final y el inicio del desarrollo de las culturas Paracas y Nasca respectivamente.

${ }^{20}$ Lidio Valdez reporta entierros con estas características en varios sitios del valle de Acarí, entre los que resulta de bastante interés algunos que presentan una especie de turbante en la cabeza y que él relaciona con una tradición local -Huarato- (Valdéz 2006: 13-17), pero que son frecuentes en Paracas Tardío y Topará.

${ }^{21}$ Geoglifos similares, especialmente figuras antropomorfas, también han sido identificados en las laderas de las planicies que bordean el valle de Ingenio.

${ }^{22}$ Nosotros, al igual que otros colegas como Patrick Carmichael (1988), consideramos que el desarrollo de la cultura Nasca como tal —entidad política y social- empieza con la fase estilística Nasca 2 y no en la fase Nasca 1. En este sentido, también pensamos que la fase Ocucaje 9 marca el final del desarrollo autónomo de la cultura Paracas. Las fases Ocucaje 10 y Nasca 1 corresponden a la época de transición entre Paracas y Nasca, la cual estaba fuertemente influenciadas por la cultura Topará.

${ }^{23}$ Las evidencias de esta época en el valle de Acarí provienen de Tambo Viejo, en donde se han documentado muros de adobe cónico y los fragmentos de cerámica semejantes a los de Cahuachi y otros sitios de Ica, Nasca y Palpa.

${ }^{24}$ Los estudios del paleoclima realizados en los valles de Palpa indican claramente que los cambios registrados en las condiciones climáticas tuvieron influencia directa en los procesos culturales (Eitel et al. 2005, Mächtle y Eitel 2013).

${ }^{25}$ En este caso es importante revisar el proceso cultural en el valle de Chincha, en donde existe un importante desarrollo Paracas que presenta un patrón de ordenamiento urbano visible en los edificios con arquitectura monumental (Canziani 2009, 2013), el cual aparentemente continua con Topará (Necrópolis) pero sobre el cual todavía falta investigar.

${ }^{26}$ Según Tinteroff, el concepto de «mutación cultural multidireccional» se refiere a la idea de continuidad sin rompimiento, es decir, a la transformación progresiva —endógena- de la cultura Paracas, cuya población cambió sus tradiciones culturales de manera distinta en los diversos valles de la costa sur. De este modo, sostiene que tres entidades culturales distintas pero contemporáneas —Paracas, Topará y Nasca- se desarrollaron e interactuaron entre los años 200 a.C. y 100 d. C. (Tinteroff 2008: 140-146).

${ }^{27}$ Los principales elementos culturales en común que comparten los paracas y los nasca comprenden a los rasgos formales e iconográficos de la cerámica y los textiles (Paul 1991; Silverman y Proulx 2002), los aspectos formales y estructurales de la arquitectura pública y ceremonial (Wallace 1986; Orefici y Drusini 2003), los tipos de deformación craneal (Weiss 1961) y la producción de geoglifos en el desierto (Reindel e Isla 2004; Reindel et al. 2006). 


\section{REFERENCIAS}

Browne, D.

1992 Further archaeological reconnaissance in the Province of Palpa, Department of Ica, Peru, en: N. J. Saunders (ed.), Ancient America: Contributions to New World archaeology, Oxbow Monograph 24, 77-116, Oxbow, Oxford.

Canziani, J.

1992 Arquitectura y urbanismo del período Paracas en el valle de Chincha, Gaceta Arqueológica Andina 22, 87-117.

2009 Ciudad y territorio en los Andes: contribuciones a la historia del urbanismo prehispánico, Fondo Editorial PUCP, Lima.

2013 Arquitectura, urbanismo y transformaciones territoriales del Período Paracas en el valle de Chincha, Boletín de Arqueología PUCP 17: 9-29.

\section{Carmichael, P. H.}

1995 Nasca Burial Patterns: social structure and mortuary ideology, en: T. D. Dillehay (ed.), Tombs for the Living: Andean Mortuary Practices, 161-187, Dumbarton Oaks Research Library and Collection, Washington, D.C.

De La Torre, J. C. y H. Van Gijseghem

2005 Excavaciones en La Puntilla (1300 - 100 a.n.e.): arqueología en la costa sur del Perú, Revista Arqueología del Siglo XXI, 286, 22-31.

DeLeonardis, L.

1997 Paracas settlement in Callango, Lower Ica Valley, 1st millennium B.C., Peru, tesis de doctorado, Department of Anthropology, School of Arts and Sciences of the Catholic University of America, Washington, D.C.

2012 Interpreting the Paracas body and its value in ancient Peru, en: J. K. Papadopoulos y G. Urton (eds.), The construction of value in the ancient world, 197-217, Cotsen Advanced Seminars (Book 5), The Cotsen Institute of Archaeology, University of California, Los Angeles.

Domenici, D.

1994 La transizione Paracas-Nasca. Nuovi dati su Cahuachi e i centri minori della valle di Nasca, Tesi di laurea in Storia e Civilitá della America Precolombiana, Universitá degli Studi di Bologna, Italia.

Dwyer, J. P.

1971 Chronology and iconography of Late Paracas and Early Nasca textile designs, tesis de doctorado, Department of Anthropology, University of California, Berkeley.

Eitel, B., S. Hecht, B. Mächtle, G. Schukraft, A. Kadereit, G. A. Wagner, B. Kromer, I. Unkel y M. Reindel

2005 Geoarchaeological evidence from desert loess in the Nazca-Palpa Region, Southern Peru: Paleoenviromental changes and their impact on Pre-Columbian cultures, Archeometry 47 (1): 137-158. https://doi.org/10.1111/j.1475-4754.2005.00193.x

Eitel, Be. y B. Mächtle

2009 Man and environment in the Eastern Atacama Desert (Southern Peru): Holocene climate changes and their impact on pre-Columbian cultures, en: M. Reindel y G. Wagner (eds.), New Technologies for Archaeology, 17-37, Natural Science in Archaeology, Springer, Berlín/Heildelberg. https://doi. org/10.1007/978-3-540-87438-6_2

Fux, P.

2012 The Petroglyphs of Chichictara, Palpa, Peru. Documentation and interpretation using terrestrial laser scanning and image-based 3D modeling, Zeitschrif für Archäologie Aussereuropäischer Kulturen 4, $127-205$.

Gorbahn, H.

2013 El sitio de Pernil Alto del Arcaico Medio en el sur del Perú: comienzo de horticultura y sedentarismo en condiciones del Holoceno Medio, Diálogo Andino 41, 61-82. 
Isla C., J.

2009 From hunters to regional Lords: Funerary practices in Palpa-Peru, en: M. Reindel y G. Wagner (eds.), New Technologies for Archaeology, 119-140, Natural Science in Archaeology, Springer, Berlín/Heildelberg. https://doi.org/10.1007/978-3-540-87438-6_8

2010 Perspectivas sobre el proceso cultural en los valles de Palpa, costa sur del Perú, en: L. Valle A. (ed.), Arqueologia y desarrollo. Experiencias y posibilidades en el Perú, 15-52, Ediciones SIAN, Trujillo.

Isla C., J., M. Reindel y J. C. de la Torre

2003 Jauranga: un sitio Paracas en el valle de Palpa, costa sur del Perú, Beiträge zur Allgemeinen und Vergleichenden Archäologie 23, 227-274.

Isla C., J. y M. Reindel

2005 New studies on the settlements and geoglyphs in Palpa, Peru, Andean Past 7, 57-92.

2007 Los Paracas del sur. Una perspectiva desde los valles de Palpa, en: Hilos del Pasado. Un aporte francés al legado Paracas, 79-91, Instituto Nacional de Cultura, Lima.

2017 Los petroglifos de Palpa: arte rupestre del período Formativo, manuscrito en poder de los autores.

2017 Palpa and Lucanas: Cultural development under changing climatic conditions on the western slope of the Andes in Southern Peru, en: A. Casey (ed.), The Andes: Geography, diversity, and sociocultural impacts, 53-119, Nova Science.

Lambers, $\mathrm{K}$.

2006 The geoglyphs of Palpa, Peru: Documentation, analysis, and interpretation, Forschungen zur Archäologie Aussereuropäischer Kulturen 2, Linden Soft, Aichwald.

Lanning, E. P.

1960 Chronological and cultural relationships of early pottery styles in ancient Perú, tesis de doctorado, Departament of Anthropology, University of California, Berkeley.

Llanos, O. D.

2007 Le bassin du Rio Grande de Nazca, Pérou. Archéologie d'un État andin, 200 av. J.- C. - 650 ap. J.- C., tesis de doctorado, Ecole des Hautes Etudes en Sciences Sociales, París.

Mächtle, B. y B. Eitel

2013 Fragile landscapes, fragile civilizations - How climate determined societies in the pre-Columbian south Peruvian Andes, Catena 103, 62-73.

Massey, S. A.

1986 Sociopolitical change in the Upper Ica Valley, B.C. 400 to 400 A.D.: Regional states on the south coast of Peru, tesis de doctorado, Department of Archaeology, University of California, Los Angeles.

1991 Paracas, en: Los Incas y el Antiguo Perú: 300 años de Historia, 230-241, Centro Cultural de la Villa Ayuntamiento de Madrid.

Matos, A.

1987 Los petroglifos de Chichictara. Lima.

Menzel, D.

1971 Estudios arqueológicos en los valles de Ica, Pisco, Chincha y Cañete, Arqueología y Sociedad 6, 1-161.

Menzel, D., J. H. Rowe y L. Dawson

1964 The Paracas pottery of Ica: A study in style and time, University of California Publications in American Archaeology and Ethnology 50, University of California Press, Berkeley.

Orefici, G.

1988 Una expresión de arquitectura monumental Paracas-Nasca: El Templo del Escalonado de Cahuachi, Atti Convegno Internazionale: Archeología, Scienza e Societa nell'America Precolombiana, 191-201, Centro Italiano Studi e Ricerche Archaeologiche Precolombiane, Brescia.

1996 Nuevos enfoques sobre la transición Paracas-Nasca en Cahuachi (Perú), ANDES, Boletín de la Misión Arqueológica Andina 1, 173-198, Universidad de Varsovia, Polonia.

Orefici, G. y A. Drusini

2003 Nasca: hipótesis y evidencias de su desarrollo cultural, Documentos e investigaciones 2, Brescia, Italia. 
Paul, A.

1982 The chronological relationship of the linear, block color, and broad line styles of Paracas embroidered images, en: A. Cordy-Collins (ed.), Pre-columbian art history: Select readings, 255-277, Peek Publications, Palo Alto.

1991 Paracas: An ancient cultural tradition on the south coast of Peru, en: A. Paul (ed.), Paracas art and architecture. Object and context in south coastal Peru, 1-34, University of Iowa Press, Iowa City.

Peters, A. H.

1997 Paracas, Topará and early Nasca: Ethnicity and society on the south central Andean coast, tesis de doctorado, Department of Anthopology, Cornell University Ithaca, Ithaca.

2013 Topará en Pisco: patrón de asentamiento y paisaje, Boletín de Arqueología PUCP 17, 77-101.

Pezzia, A.

1968 Ica y el Perú precolombino. Tomo I: Arqueología de la Provincia de Ica, Editorial Ojeda, Ica.

Proulx, D. A.

1970 Nasca gravelots in the Uhle collection from the Ica Valley, Peru, Research report, Department of Anthropology, University of Massachusetts, Amherst.

2006 A sourcebook of Nasca ceramic iconography. reading a culture through its art, University of Iowa Press, Iowa City. https://doi.org/10.2307/j.ctt20ks1n8

Reindel, $\mathrm{M}$.

2009 Life at the edge of the desert - Archaeological reconstruction of the settlement history in the Valleys of Palpa, Peru, en: M. Reindel y G. Wagner (eds.), New Technologies for Archaeology. Multidisciplinary Investigations in Palpa and Nasca, Peru, 439-461, Natural Science in Archaeology, Springer, Berlín/ Heildelberg.

Reindel, M. y J. Isla

2001 Los molinos und La Muña. Zwei siedlungszentren der Nasca-Kultur in Palpa, Südperu. Los Molinos y La Muña. Dos centros administrativos de la cultura Nasca en Palpa, costa sur del Perú, Beiträge zur Allgemeinen und Vergleichenden Archäologie 21, 241-319.

2004 Archäologisches projekt Paracas in Palpa, Peru. Bericht über die Grabungskampagne 2003, SLSAJahresbericht 2003, 137-156, Schweizerisch-Liechtensteinischen Stiftung für archäologische Forschungen im Ausland, Vaduz y Zürich.

2006 Evidencias de culturas tempranas de los valles de Palpa, costa sur del Perú, Boletín de Arqueología PUCP 10, 237-283.

2009 El Período Inicial en Pernil Alto, Palpa, costa sur del Perú, Boletín de Arqueología PUCP 13, $259-288$.

2013 Cambio climático y patrones de asentamiento en la vertiente occidental de los Andes del sur del Perú, Diálogo Andino 41, 83-99.

Reindel, M., J. Isla y K. Koschmieder

1999 Vorspanische Siedlungen und Bodenzeichnungen in Palpa, Süd-Perú. Asentamientos prehispánicos y geoglifos en Palpa, costa sur del Perú, Beiträge zur Allgemeinen und Vergleichenden Archäologie 19, 313-381.

Reindel, M., K. Lambers y A. Grün

2003 Photogrammetrische dokumentation und archäologische analyse der vorspanischen Bodenzeichnungen von Palpa, Süd-Peru. Documentación fotogramétrica y análisis arqueológico de los geoglifos prehispánicos de Palpa, costa sur del Perú, Beiträge zur Allgemeinen und Vergleichenden Archäologie 23, 183-226.

Reindel, M., J. Isla y K.Lambers

2006 Los geoglifos de Palpa: documentación, análisis y perspectivas, Boletín de Lima (XXVIII) 143, 73-111.

Rowe, J. H.

1958 La seriación cronológica de la cerámica Paracas elaborada por Lawrence E. Dawson, Revista del Museo Regional de Ica 10, 9-21.

1960 Nuevos datos relativos a la cronología del estilo Nasca, en: R. Matos M. (ed.), Antiguo Perú: espacio y tiempo, 29-45, Editorial Juan Mejía Baca, Lima. 
Sawyer, A.

1966 Ancient Peruvian ceramics: The Nathan Cummings collection, Metropolitan Museum of Art, New York.

Schreiber, K. J.

1998 Nasca research since 1926, en: [A. L. Kroeber, D. Collier], P. H. Carmichael (ed.), The archaeology and pottery of Nazca, Perú: Alfred L. Kroeber's 1926 expedition, 261-270. Altamira, Walnut Creek.

Schreiber, K. J. y J. Lancho

2003 Irrigation and Society in the Peruvian Desert: The Puquios of Nasca, Lexington Books, Landham.

Silverman, $\mathrm{H}$.

1993 Cahuachi in the ancient Nasca world, University of Iowa Press, Iowa City.

1994 Paracas in Nazca: New data on the Early Horizon occupation of the Río Grande de Nazca Drainage, Peru, Latin American Antiquity 5 (4), 359-382.

1996 The Formative Period on the south coast of Peru: A critical review, Journal of World Prehistory 10(2), 95-146.

2002 Ancient Nasca settlement and society, University of Iowa Press, Iowa City.

Silverman, H. I. y D. Proulx

2002 The Nasca, Blackwell Publishers, Malden.

Strong, W. D.

1957 Paracas, Nazca, and Tiahuanacoid cultural relationships in south coastal Peru, Memoirs of the Society for American Archaeology 13, The Society for American Archaeology, Salt Lake City, Utah.

Tantaleán, H., C. Stanish, M. Zegarra, K. Pérez y B. Nigra

2013 Paracas en el valle de Chincha: nuevos datos y explicaciones, Boletin de Arqueología PUCP 17, 31-56.

Tinteroff, V.

2008 De Paracas à Nasca sur la côte sud du Pérou. Archaéologie d'une mutation culturelle, tesis de doctorado, l'Université Paris Sorbonne (Paris IV). École Doctorale VI - Histoire de l'Art et Archaéologie.

Tomasto-Cagigao, E., M. Reindel y J. Isla

2015 Paracas funerary practices in Palpa, South coast of Peru, en: P. Eeckhout y L. S. Owens (eds.), Funerary practices and models in the ancient Andes: The return of the living dead, 69-86, Cambridge University Press, New York. https://doi.org/10.1017/cbo9781107444928.007

Unkel, I., B. Kromer, M. Reindel, L. Wacker y G.A. Wagner

2007 A chronology of the pre-Columbian Paracas and Nasca culture in the South Peru based on AMS-14C dating, Radiocarbon 49, 551-564. https://doi.org/10.1017/s0033822200042466

Unkel, I., M. Reindel, H. Gorbahn, J. Isla B. Kromer y V. Sossna

2012 A comprehensive numerical chronology for the pre-Columbian cultures of the Palpa valleys, south coast of Peru, Journal of Archaeological Science 39, 2294-2303. https://doi.org/10.1016/j.jas.2012.02.021

Valdéz, L.

2000 La tradición Huarato de Acarí y sus relaciones con Nasca, Arqueología y Sociedad 13, 159-171.

2006 Los vecinos de Nasca: entierros de la tradición Huarato del valle de Acarí, Perú, Bulletin de l'Institut Français d' Études Andines 35(1), 1-20. https://doi.org/10.4000/bifea.4717

Van Gijseghem, $\mathrm{H}$.

2004 Migration, agency, and social change on a prehistoric frontier: The Paracas-Nasca transition in the southern Nasca Drainage, Peru, tesis de doctorado, University of California, Santa Barbara.

2006 A frontier perspective on Paracas society and Nasca ethnogenesis, Latin American Antiquity 17 (4), 419-444. https://doi.org/10.2307/25063066

Vaughn, K. J.

2004 Households, crafts, and feasting in the ancient Andes: the village context of early Nasca craft comsumption, Latin American Antiquity 15, 61-88. https://doi.org/10.2307/4141564

Vaughn, K. J. y H. Van Gijseghem

2007 A compositional perspective on the origins of the Nasca cult, Journal of Archaeological Science 34, 814-822. https://doi.org/10.1016/j.jas.2006.08.008 
Wallace, D.

1985 Paracas in Chincha and Pisco: A reappraisal of the Ocucaje sequence, en: D. H. Sandweiss y D. P. Kvietok (eds.), Recent Studies in Andean Prehistory and Protohistory, 67-94, Cornell University Latin American Studies Program, Ithaca.

1986 The Topará tradition: An overview, en: D.H. Sandweiss y D. P. Kvietok (eds.), Perspectives on Andean Prehistory and Protohistory, 35-47, Cornell University Latin American Studies Program, Ithaca.

Weiss, P.

1961 Osteología cultural. Prácticas cefálicas, Universidad Nacional Mayor de San Marcos, Lima.

Recepción: 4/VI/2018

Aceptación: 17/VII/2018 